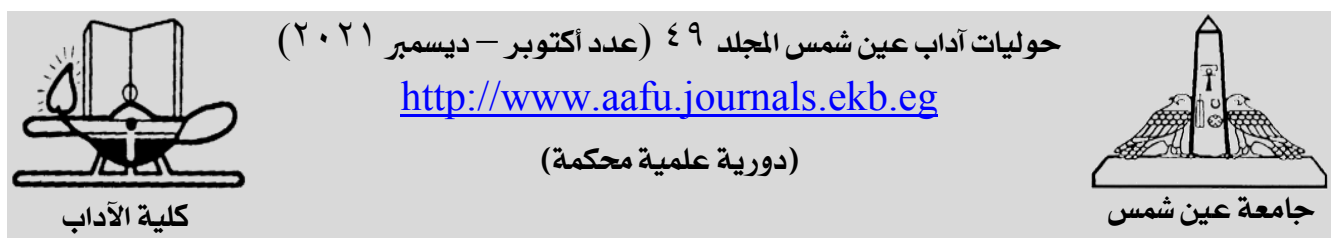

\title{
تناول الصحف البحرينية للأخبار السياسية وتأثيرها على الرأي العام
}

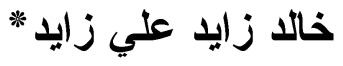

قسم علوم الاتصال و الإعلام / كلية الاداب/ جامعة عين شمس/مصر

k.zayeda@gmail.com

تُمَنِّل الصحافة المكتوبة في مملكة البحرين أحد أبرز قنوات التأثير على توجهـات

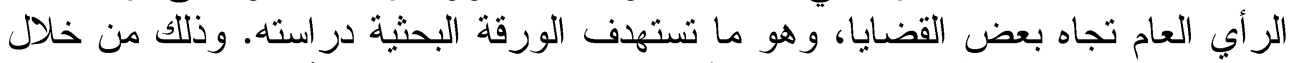

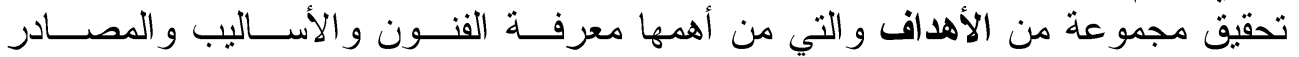

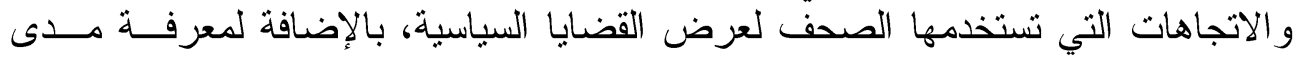

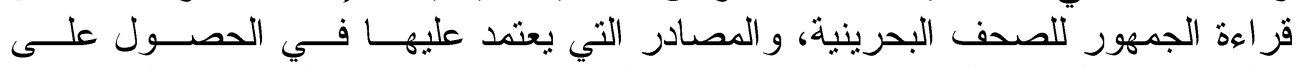

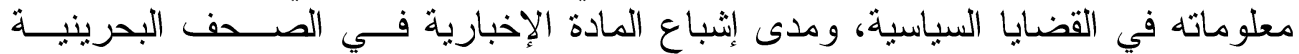
احتياجات الجمهور نحو القضايا السياسية.

و اعتمدت الدر اسة على منهج المسح الإعلامي، واستخدام أدوات التهيل تحليل المضمون

$$
\text { واستمارة الاستبيان لجمع البيانات. }
$$

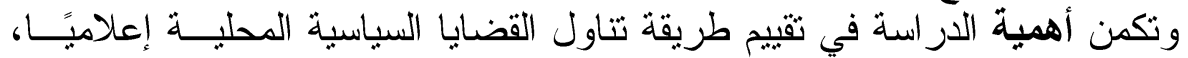

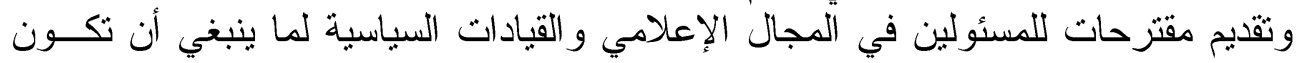

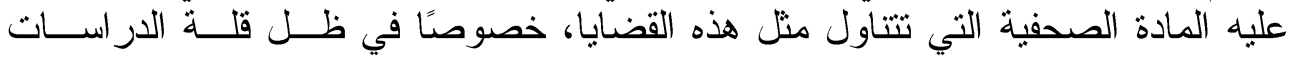

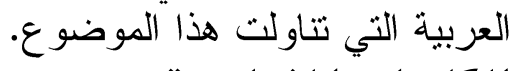

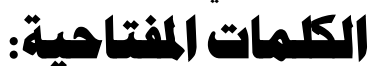

الر أي العام، المعالجة الإعلامية، الأطر، اتجاهات الجمهور، القضايا السياسية. 


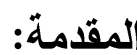

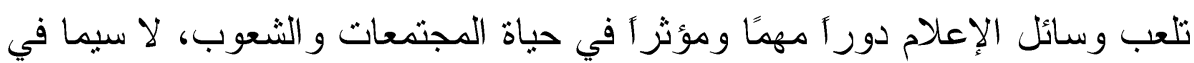

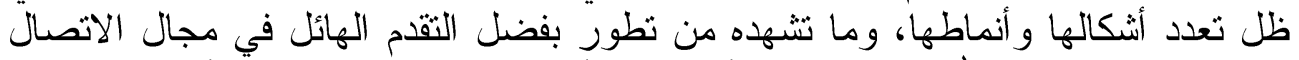

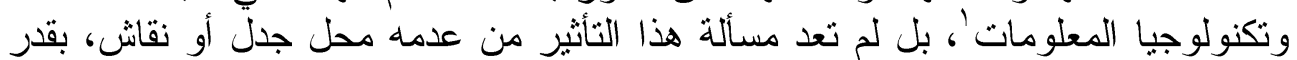

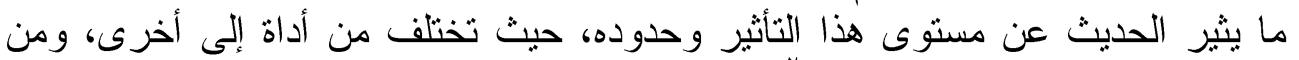

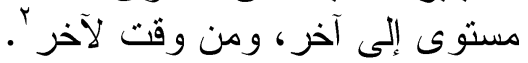

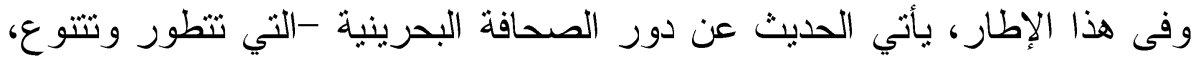
سو اء من حيث عدد الصحف أو من حيث تتاولها لهان لمختلف القضايا- في تشكيل الر أي العام وتتسم بيئة العمل الصحفية بنوع من التعقيد البيئي تبعًا لتنوع حاجات الجمهور في البحريني.

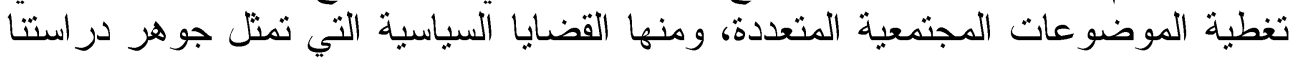

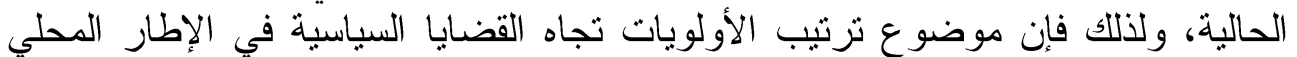

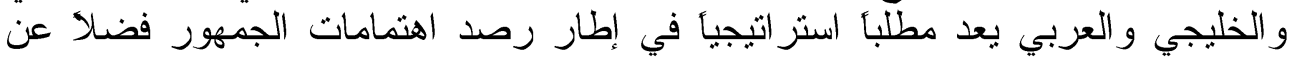

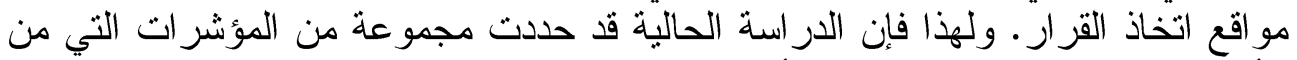

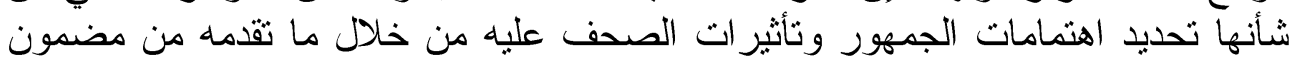

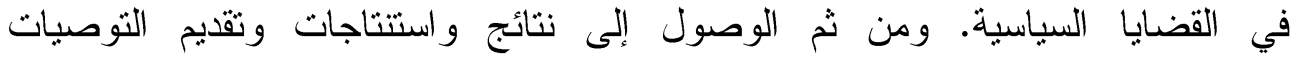
و آلمقتز حات المناسبة. أهداف الار (سية: ترمي الدراسة لتحقيق مجمو عة من الأهداف و هي: - - تحديد حجم ودرجة اهنمام الصحف البحرينية بالقضايا السياسية. - معرفة طرق معالجة الصحافة البحرينية للقضايا السياسية. - - بيان الاشكال الصحفية التي المستخدمة في تتاول القضايا السياسية. - - التعرف على موقف و اتجاه عبنة الدر اسة نحو معالجة الصحف البحرينية للقضايا السباسبة.

الإر اسات السابقة:

تتعدد الدراسات السابقة سو اءً التي درست المعالجة الإعلامية للقضــايا السياســبة

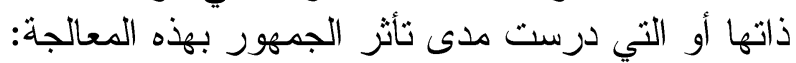

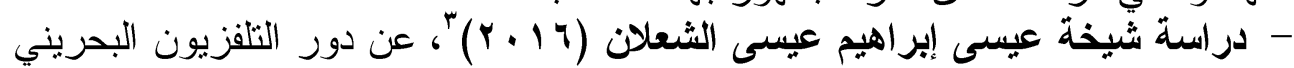

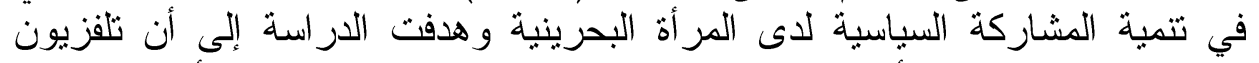

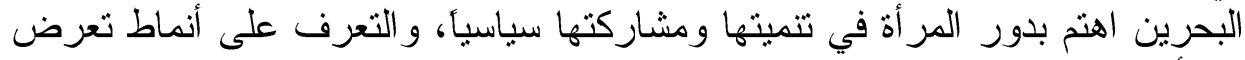

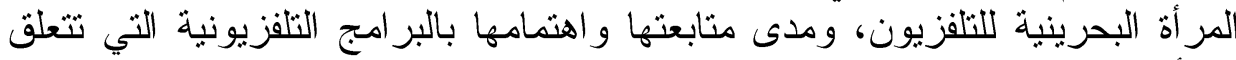

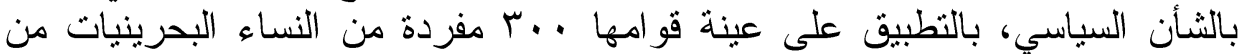
محافظات مملكة البحرين الأبطين عأربعة.

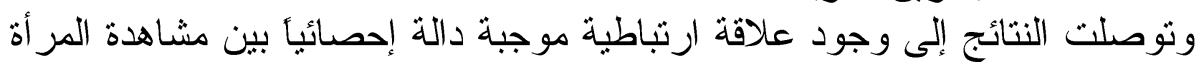

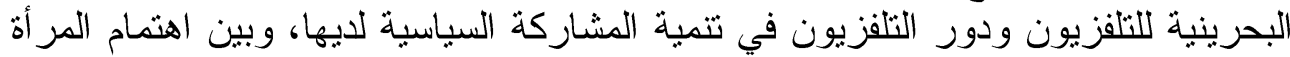

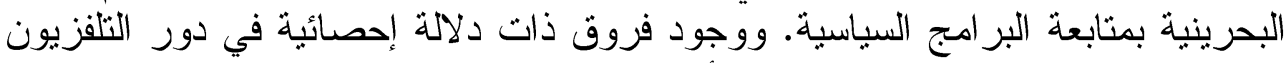

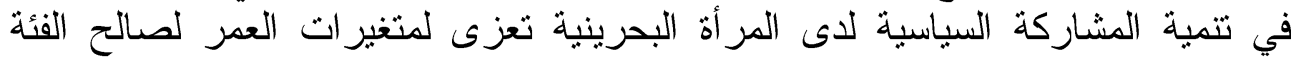


العمرية، و المؤهل العلمي، و الحالة المهنية، و عدم وجود فروق ذات دلالة إحصائية تعزي لمتغير ات الحالة الاجتماعية ومحل الإقامة ومستوى ولئة الإخل.

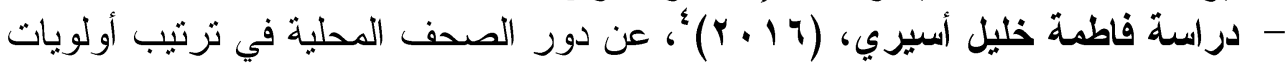

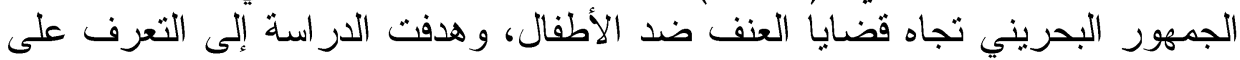

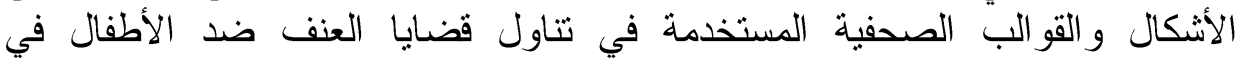
الصحف البحرينية، والتعرف على مدى وجود تفاوت بين أولويات الصحف الصات البحرينية

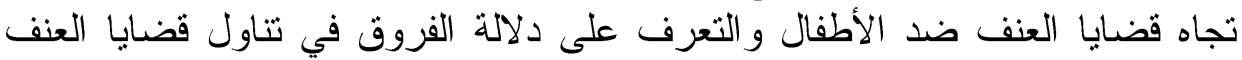

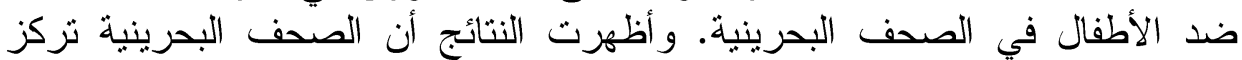
على الخبر الصحفي بدرجة كبيرة في تتاولها قضايا العنف ضد الهان الأطفال بنسبة

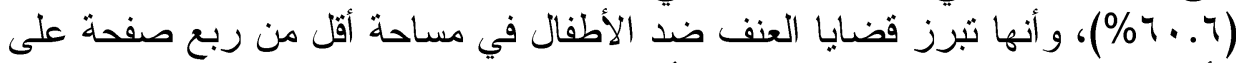

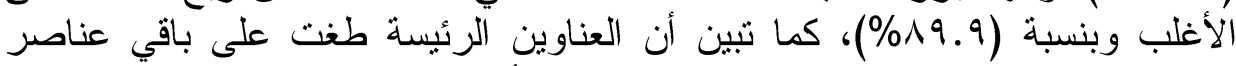

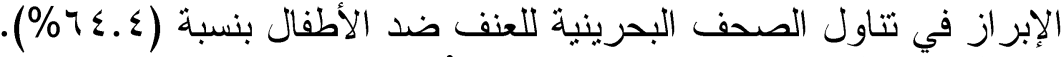

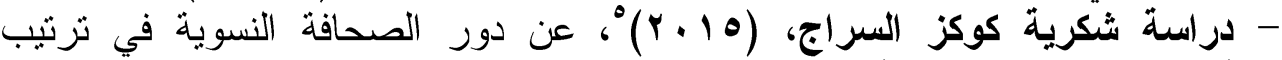

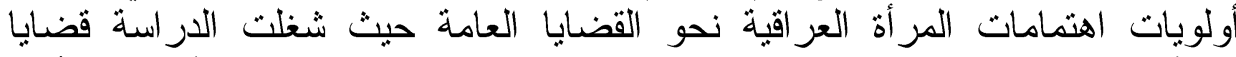

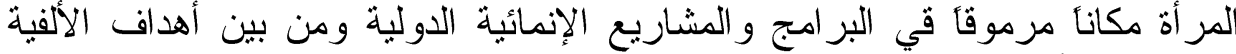

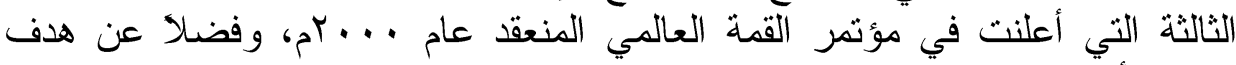

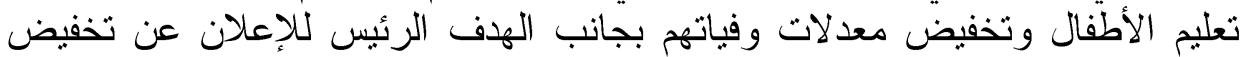

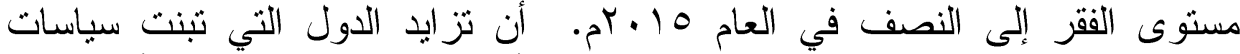

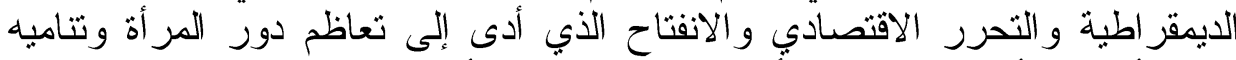

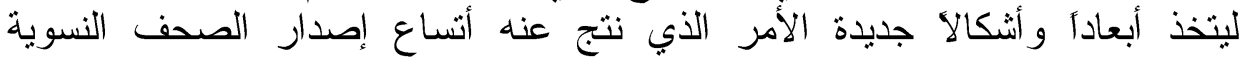

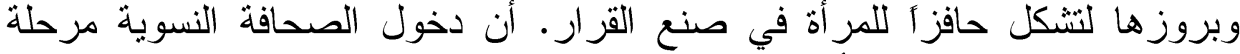

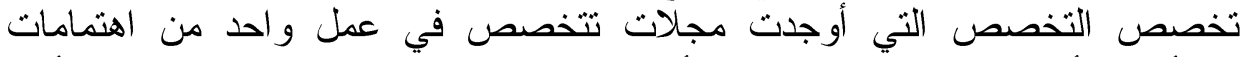

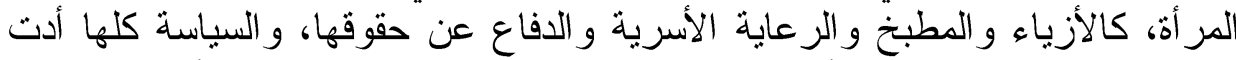

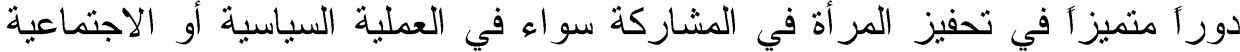

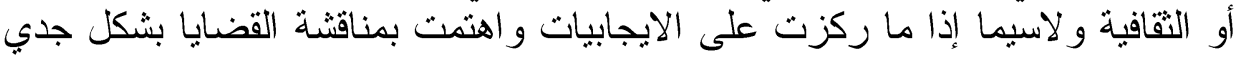
وفاعل عن طريق مجالين هما صفحات المرأة في الجرائد الئد اليومية العامة أو المجلات النسوية المتخصصة.

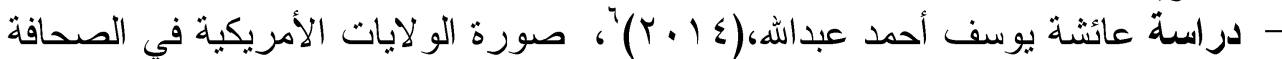

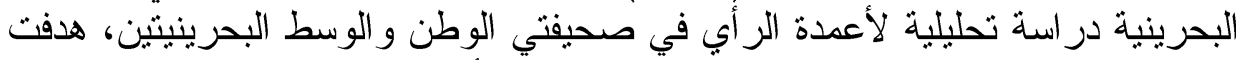

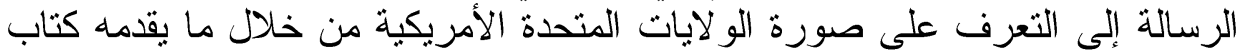

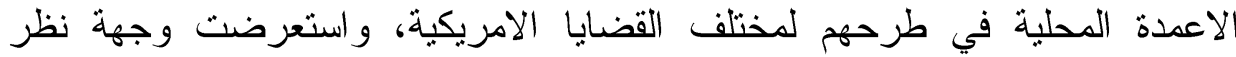

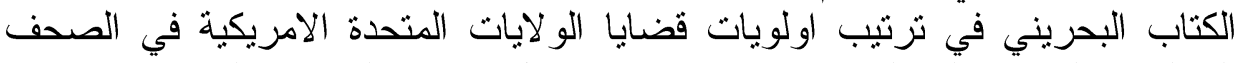

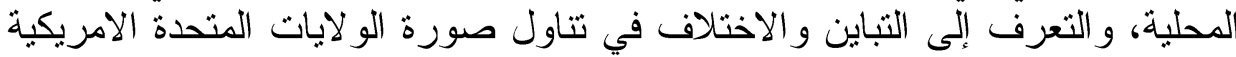

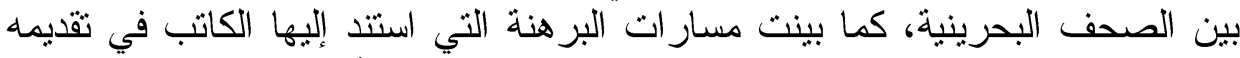

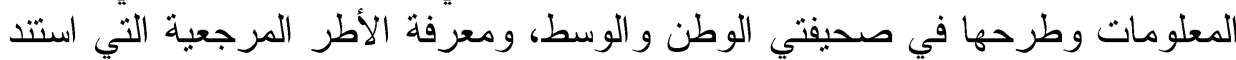

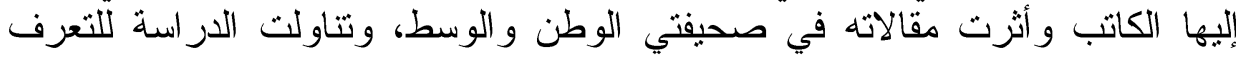

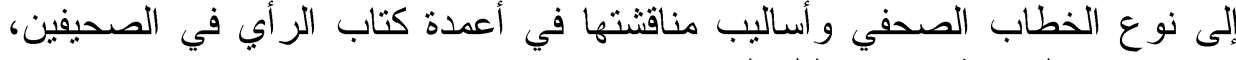

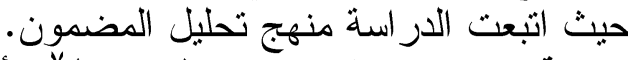

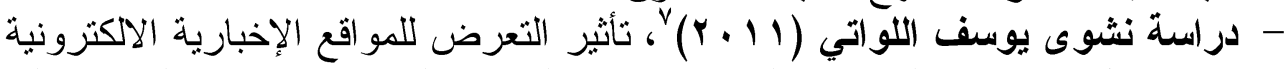

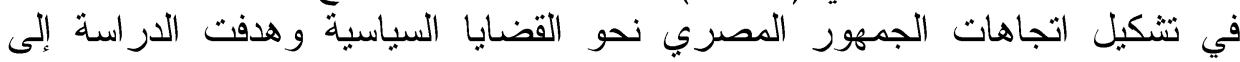




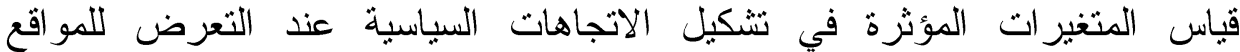

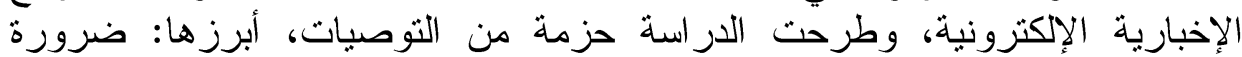

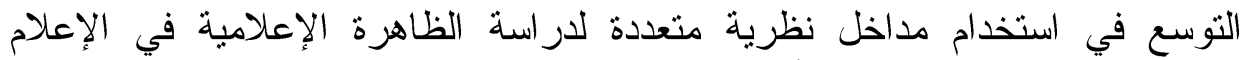

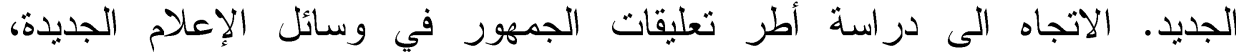

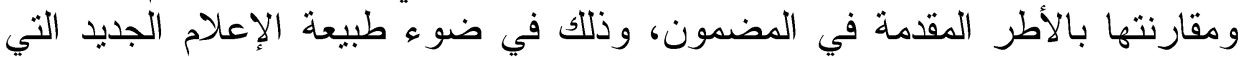

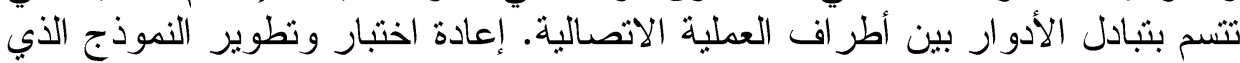

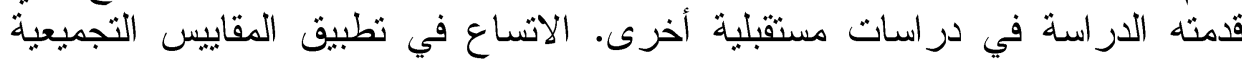
للوصول الى نتائج بشأن القياسات و المتغيرات المختلفة للإر اسة مما بعطى مؤشرات التشات ونتائج أقرب للإقة.

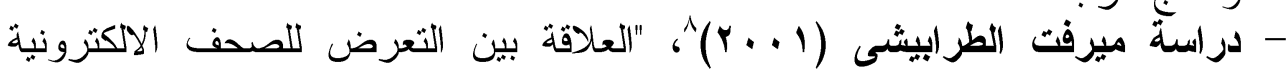

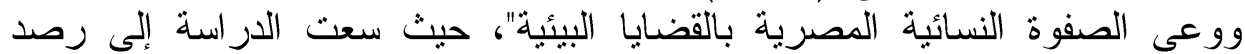

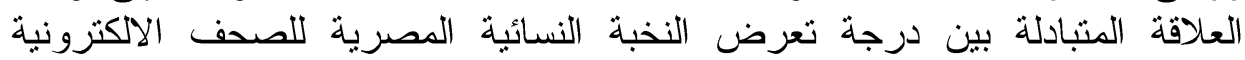

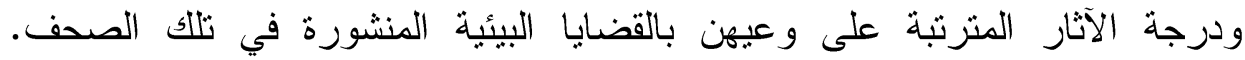

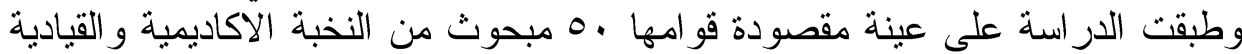

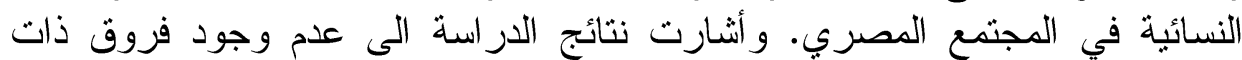

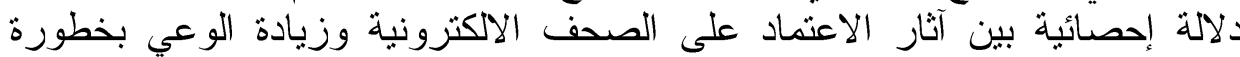
القضايا و المشكلات البيئية بين جمهور النخبة النسائية المصرية القيادية و الأكاديمية.

- Harris, Phil \& Others (2001) ${ }^{9}$, who sets the Agenda? On analysis of agenda setting the press and television coverage in the 1999 Greek European election .

انطلقت الدر اسة من افتر اض أن المضامين الإخبارية في الصحف او التلإنزيون على حد سو اء تقوم بدور فعال ومؤثر في ترنيب أولويات الجمهور اليوناني في في الحمات التهات

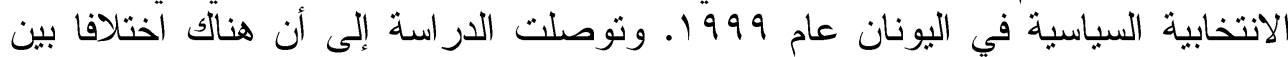

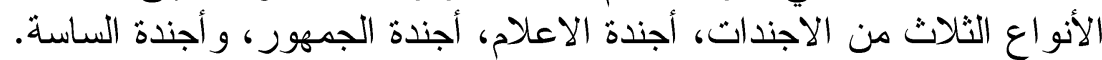

- Jessica T. Feezell, Agenda Setting through Social Media: The Importance of Incidental News Exposure and Social Filtering in the Digital Era, Political Research Quarterly, Volume: 71 issue: 2, 2017 page(s): 482$494^{10}$

تتاولت الار اسة موضوع التعرض والانتقاء الاجتماعي في العصر الرقاتمي في

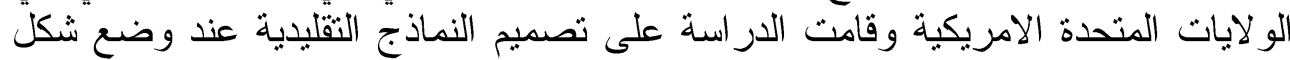

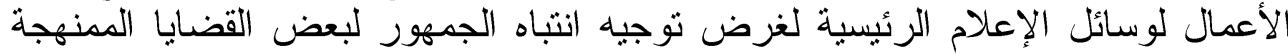

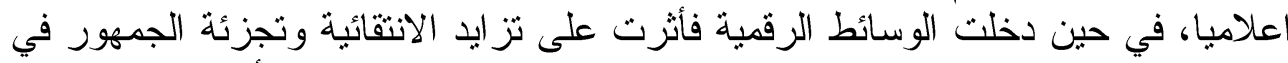

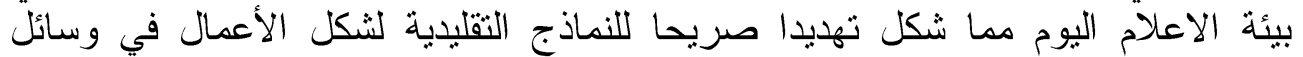

وقامت الدراسة على اختبار ما إذا كان التعرض للمعلومات السياسية من خلال

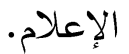

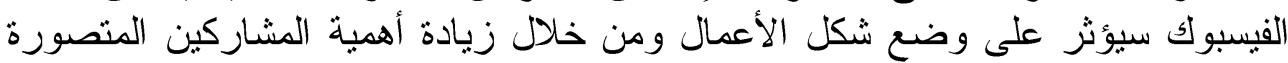
لقضايا سياسية معينة.

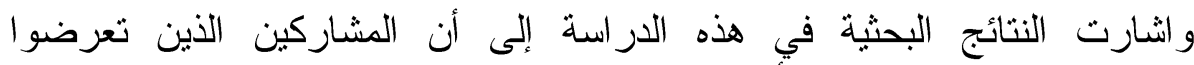

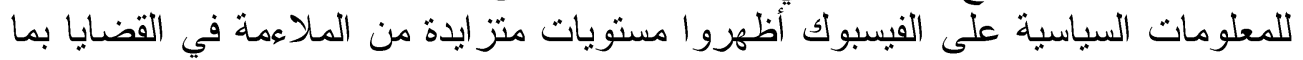


يتفق مع القضايا المشتركة مقارنة بالمشاركين الذين لم يتم عرضهم المعلومات السياسية.

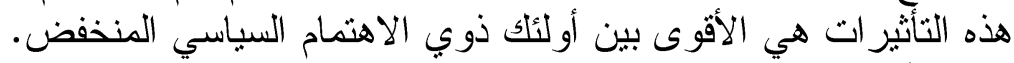

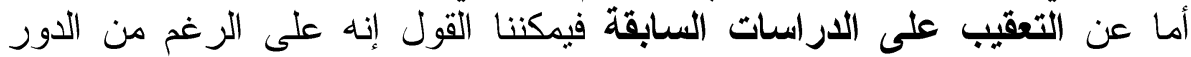

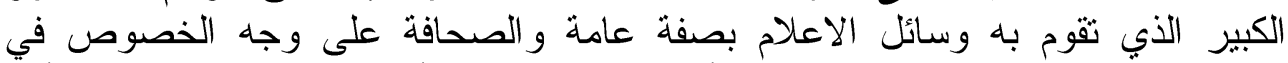

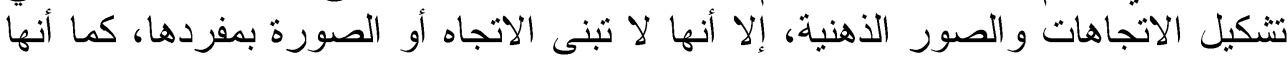

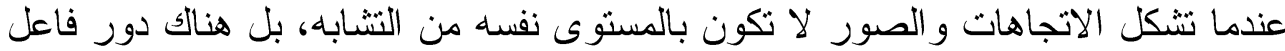

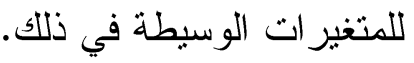

• تباينت النتائج بشأن تأثير المتغيرات الوسيطة في عملية وضع أجندة الاعلام لأجندة

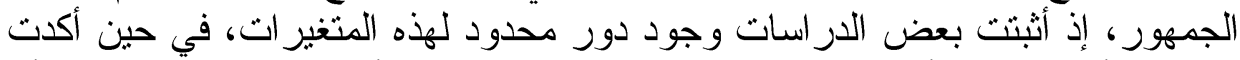

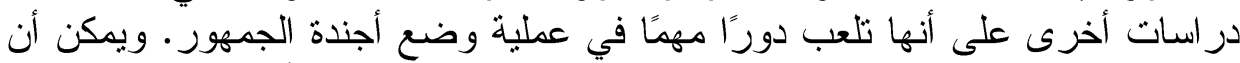
يُفسر هذا التباين في ضوء طبيعة كل دراسة والمجنمع الذي أجريت فيه وطبيعة الوسيلة و القضايا المدروسة.

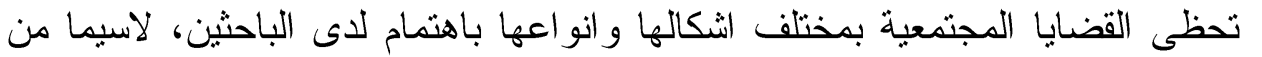

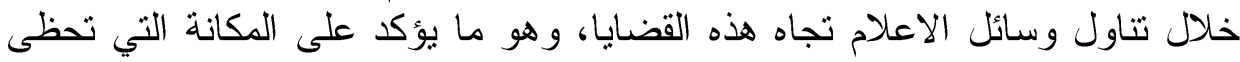

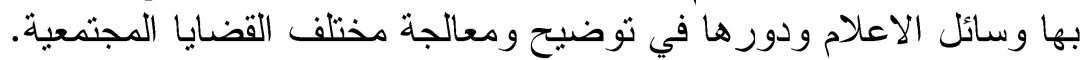

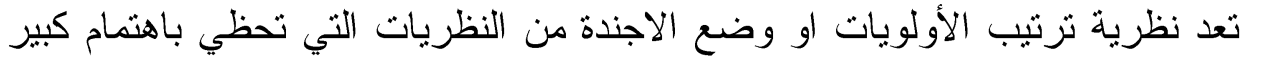

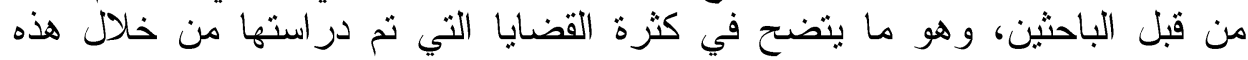
النظرية.

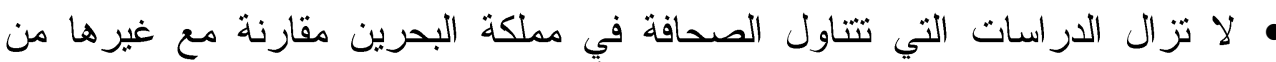

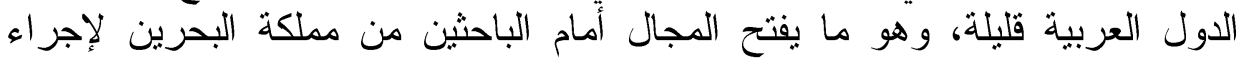

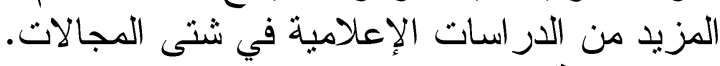

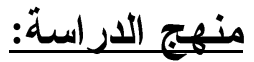

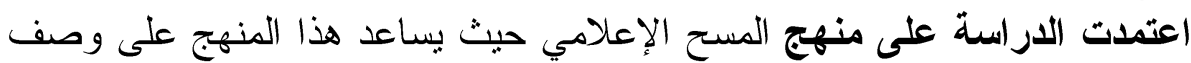

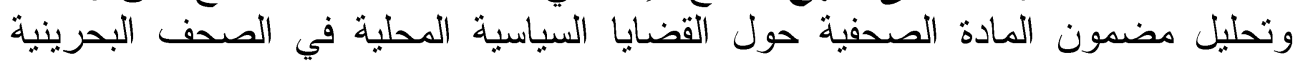
بالإضافة لدر اسة آر اء الجمهور بحسب المنئ استمار ات الاستبيان. تساؤلات الأر اسـة: بأنة

يمكن تحقيق الأهداف السابقة عن طريق الإجابة على مجموعتين من الأسئلة، أما

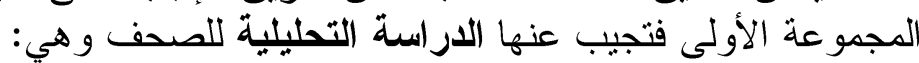
- ما الفنون الصحفية التي استخدمنها الصحف في عرض الصف القضايا السياسية؟

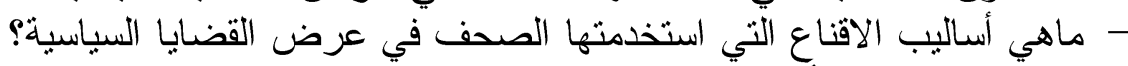

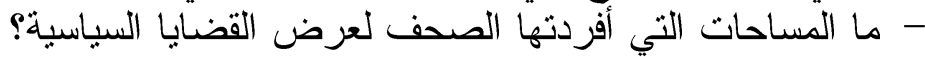

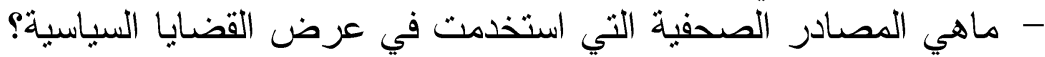

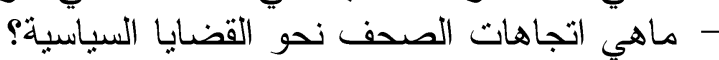

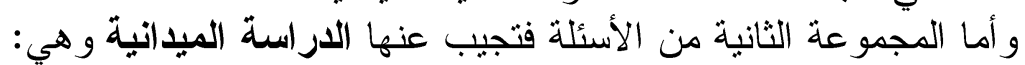

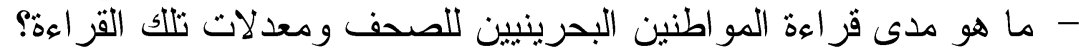

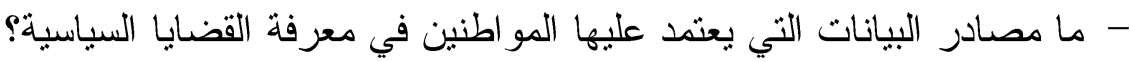

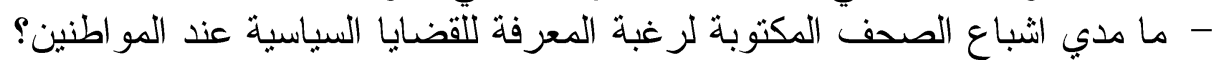

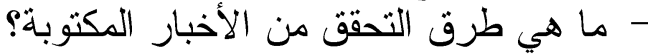
- ما قدرة الصحف البحرينية على التأثير على الجمهور في القضايا السياسية؟ 
الإجراءات المنهيبة للارسة استة:

لتطبيق منهج المسح الإعلامي في الدراسة مجموعة من الإن الأدوات التي سيلي ذكرها في الصفحات القادمة، ولكن قبل الثشروع في نتاول أدوات الدراسة بنديغي تحديد عينة

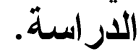

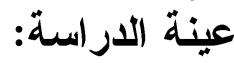

وتنقسم إلى عينة من الصحف البحرينية وتتمثل في الصحف البحرينية التي البي

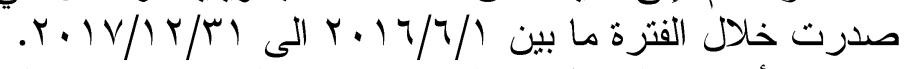

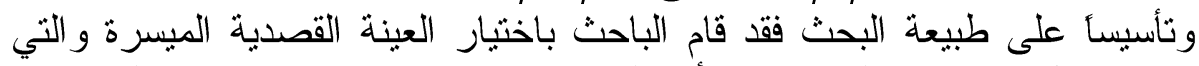

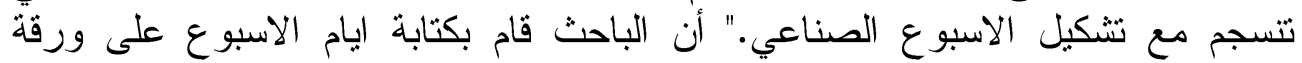

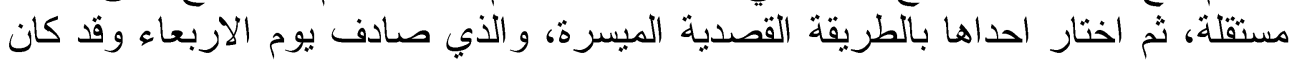

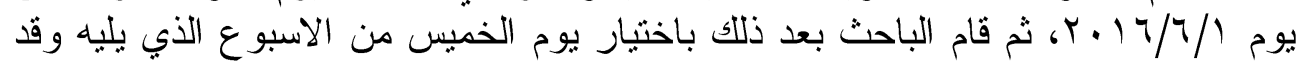

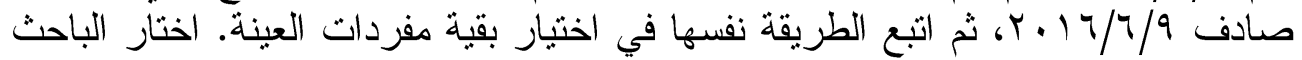

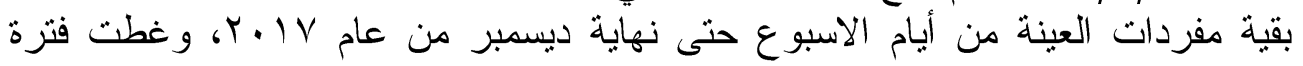

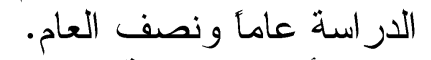

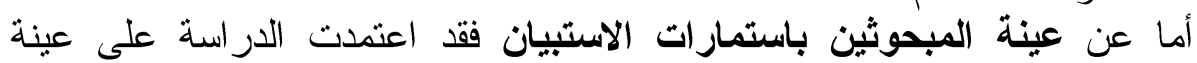

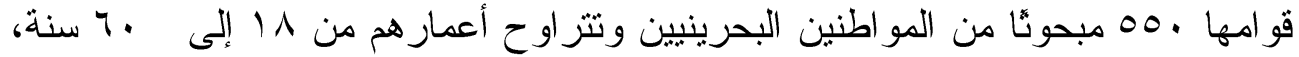

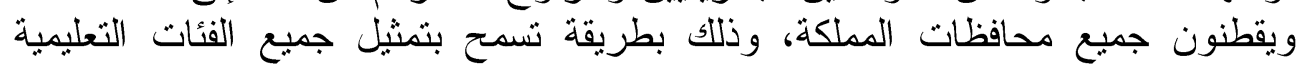

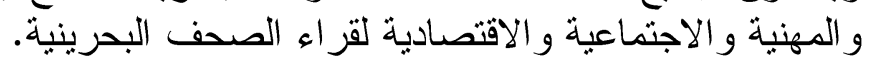

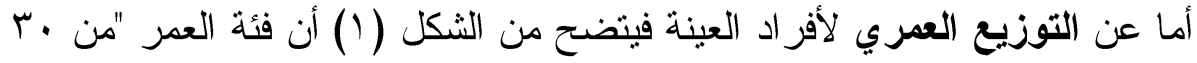

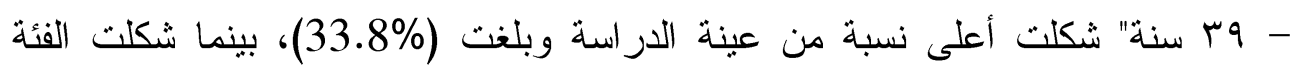
العمرية "من 11 - وج سنة" (12.5\%) وهي أقل نسبة من عينة الدراسة. شكل (1) التوزيع العمري لأفراد عينة الدراسة عنة

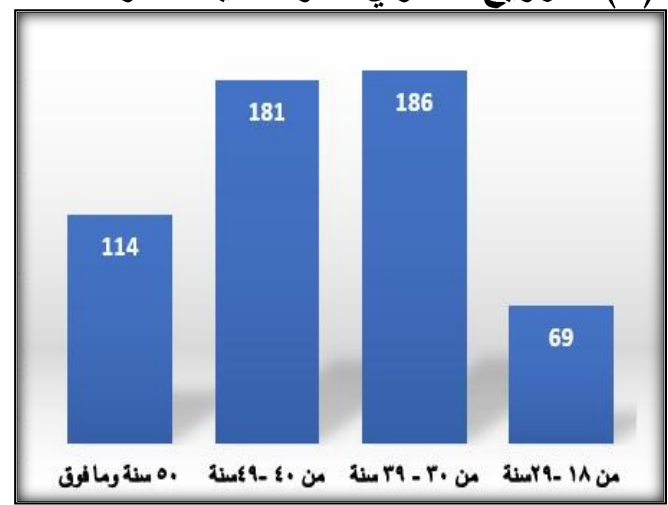

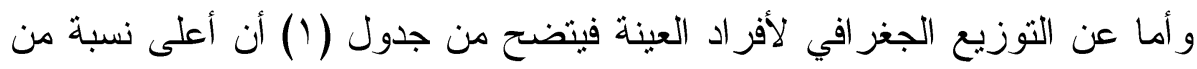

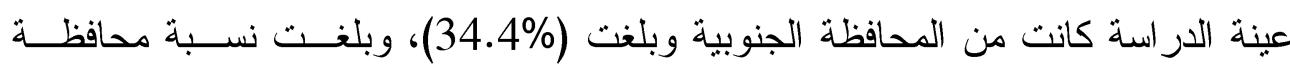
المحرق (28.4\%)، ونسبة المحافظة الثمالية (22.4\%)، وكانت أقل نسبة مسن عينــة

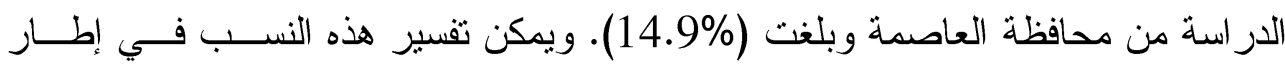

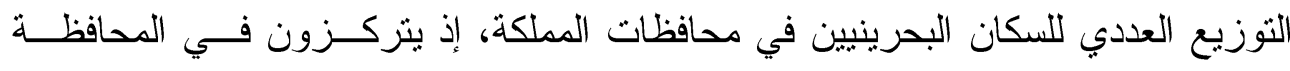


الجنوبية وتكون أقل نسبة تو اجد لهم بمحافظة العاصمة. بينما تكاد جزر حوار تخلو مــن السكان.

وتم إجر اء اختبار الثبات لاستمارة الاستبيان عن طريق إعادة تطبيق الاسـتمارة

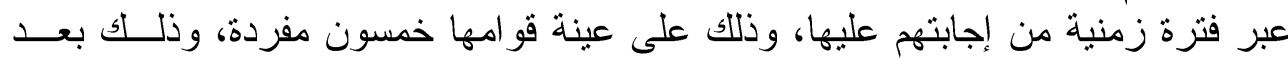

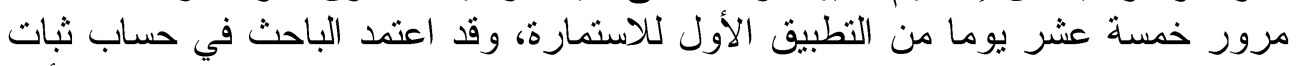

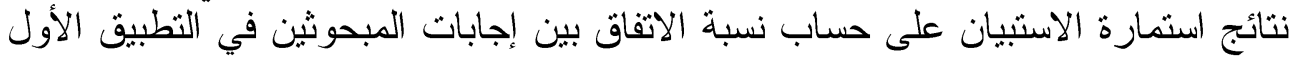

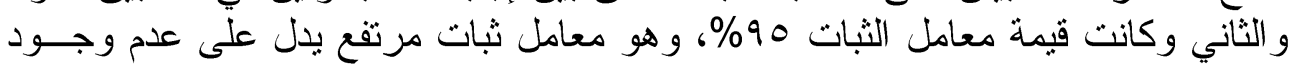

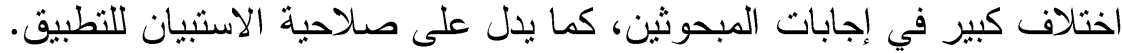
جدول (1) توزيع عينة الار اسة حسب متغير مكان الإقامة

\begin{tabular}{|c|c|c|}
\hline النسبة المئوية & العدد & مكان الإقّامة \\
\hline $28.4 \%$ & 156 & محافظة المحرق \\
\hline $14.9 \%$ & 82 & محافظة العاصمة \\
\hline $22.4 \%$ & 123 & المحافظة الشمالية \\
\hline $34.4 \%$ & 189 & المحافظة الجنوبية \\
\hline $100 \%$ & 550 & المجموع \\
\hline
\end{tabular}

المعالجة الإحصائية لاستمار اث الاستبيان:

تم تفريغ بيانات الاستبيانات ومعالجتها باستخدام حزمة البر امج SPSS و اســتخدام

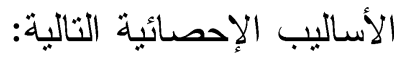

$$
\text { التكر ار ات البسبطة و النسب المئوية. }
$$

مقاييس الصدق و الثبات (كاب)، و اختبار الفا كرنباخ.

\section{مصطلحات الآر استة:}

وقد استخدمت الدراسة مجموعة من المصطلحات التي يجب تعريفها قبل الثروع في تناول النتائج وتضم المصطلحات التاندات التالية: المعالجة الإعلامية: ويقصد بها التعامل مع المعلومات الإعلامية (نصوصأ وصورأ)

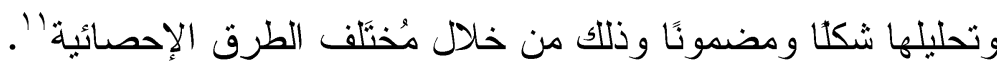

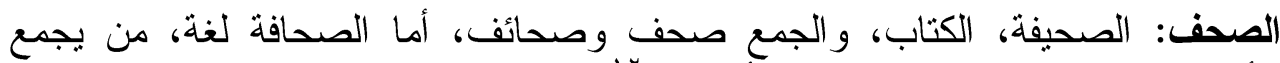

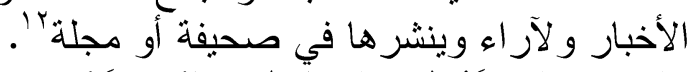

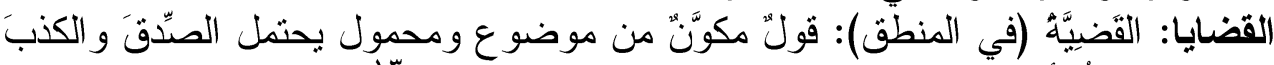

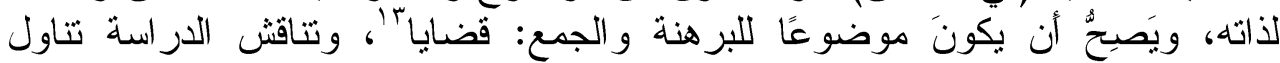

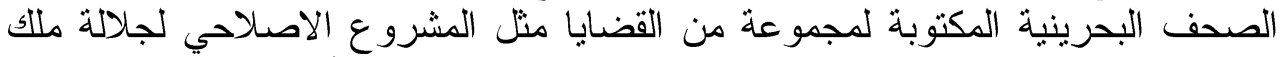

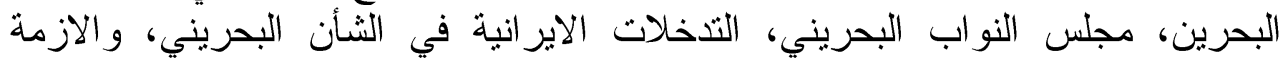




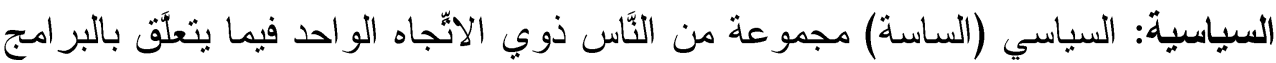

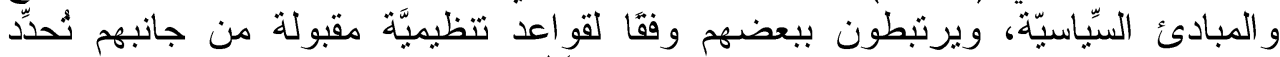

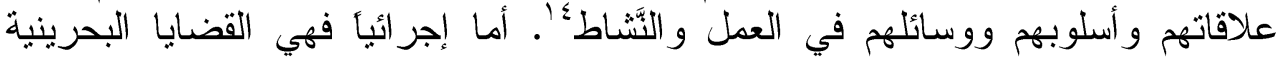
السياسية المطروحة على الساحة، و التي تعد من القضايا الاساسية التي تدور في فلكها

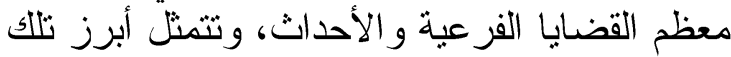

أجندة الصحف: هي القائمة التي ترثب فيها الصحف البحزي البرينية - محل الدر اسة - القضايا

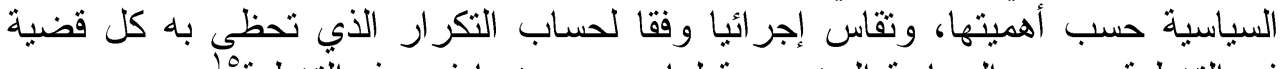

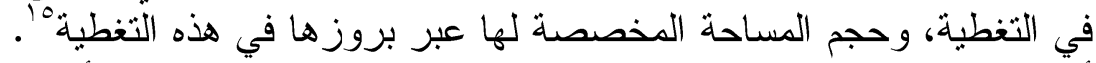

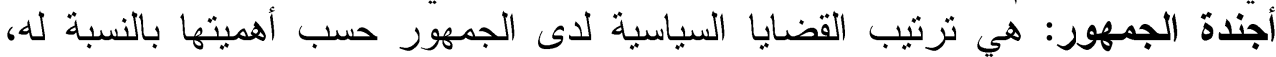
وتقاس اجر ائيا من خلال حساب تكرار ات ورود كل قضية في إجابات المبحوثين.

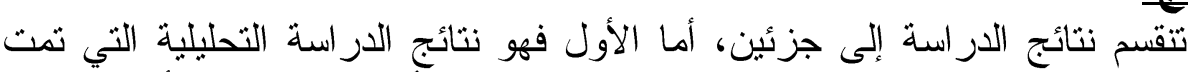
النتائجج:

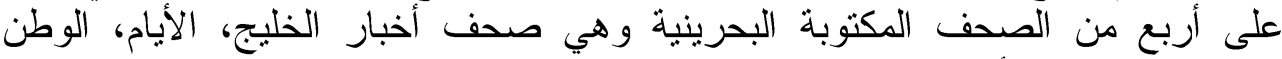

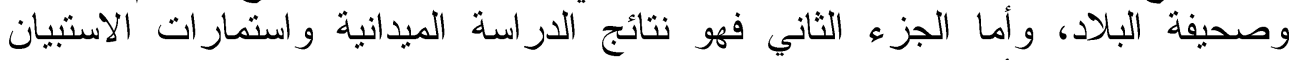

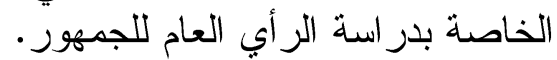

\section{(أ) نتائج الادر اسة التحليلية:}

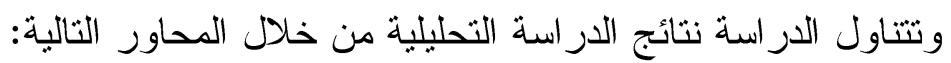
- الفنون الصحفية التي استخدمتها الصحف في عرض القالئ القضايا السياسية. - أساليب الاقناع التي أستخدمتها الصحف في عرض القضائ القضايا السياسية.

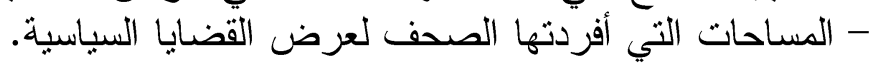
- المكان المخصص لعرض القضايا السياسية في الصحف البحفي البحرينية. - المصادر الصحفية التي استخدمت في عرض القضائ القضايا السياسية. - اتجاهات الصحف نحو القضايا السياسية.

1- الفنون الصحفية التي استخدمتها الصحف في عرضية الصناية القضايا السياسية: يوضح شكل (r) أن أكثر الفنون الصحفية التي استخدمنها الصحف الصف البحرينية لعرض القضايا السياسية هو "الخبر الصحفي" بتكرار (875) ونسبة مئوية (74.0\%)، تلاه في المرنبة الثانية "العمود" بتكرار (198) ونسبة مئوية (16.7\%)، ثم "المقال التحليلي" في المرتبة الثالثة بتكرار (52) ونسبة مئوية (4.4\%)، وفي المرنبة الرابعة "التقرير" بتكر ار (47) ونسبة مئوية (4.0\%)، ثم "المقابلة" في المرنبة الخامسة بتكر ار (5) مرة ونسبة مئوية (0.4\%). 


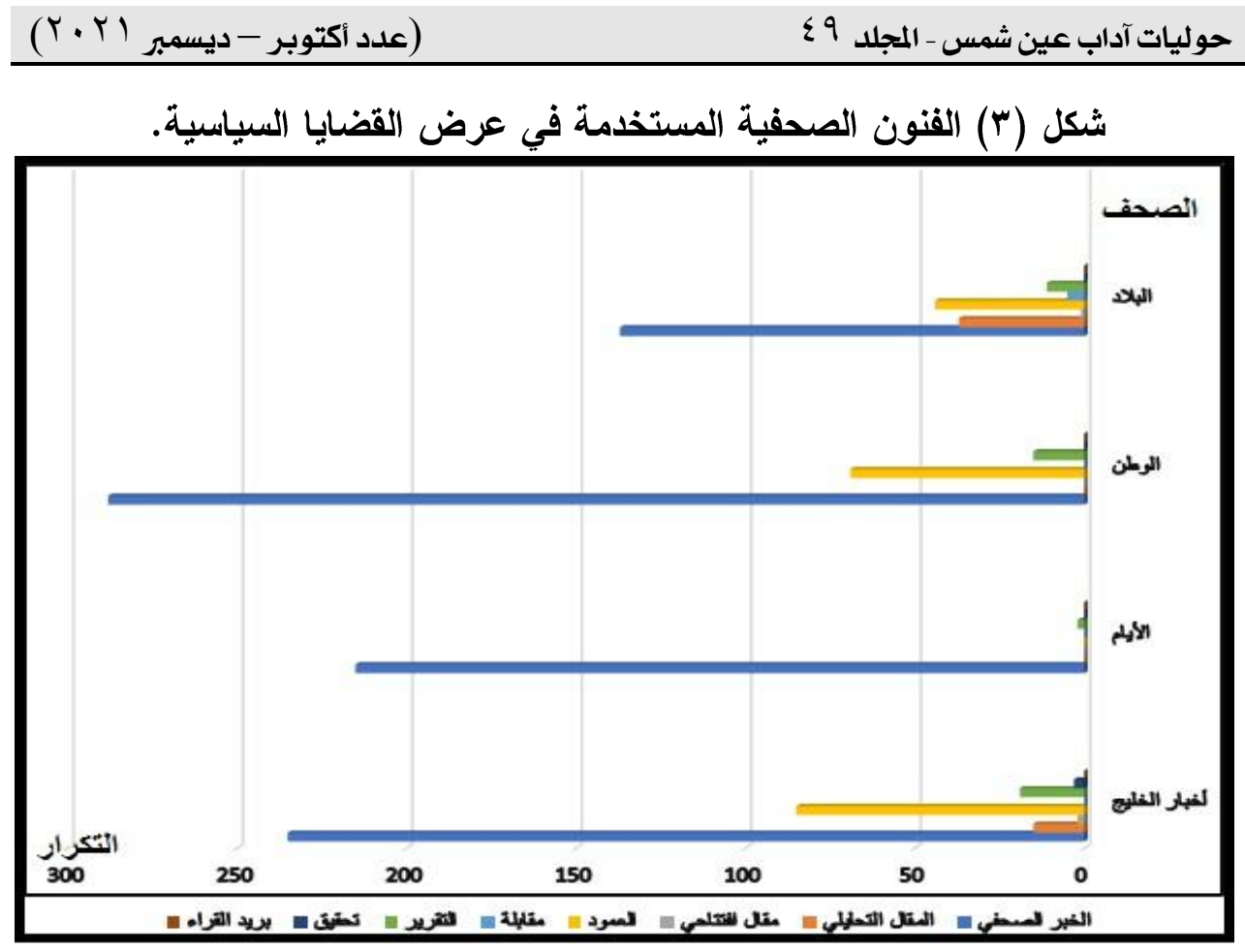

r- أساليب الاقتاع التي استخدمتها الصحف في عرض القضايا السياسية:

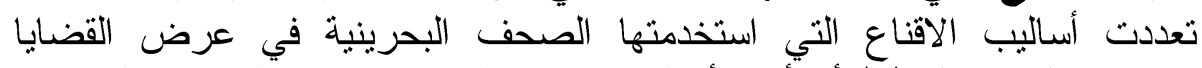

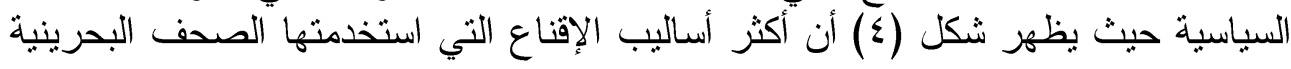

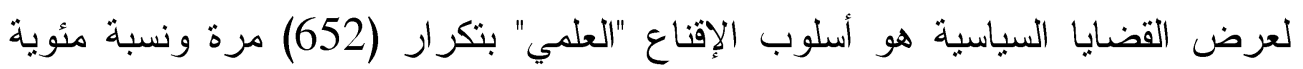

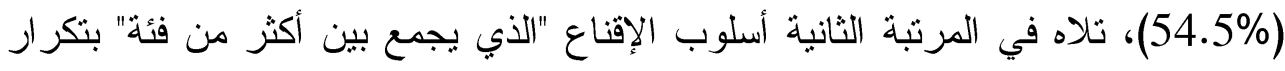

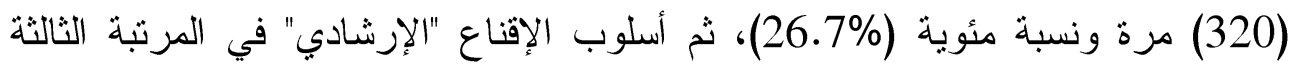

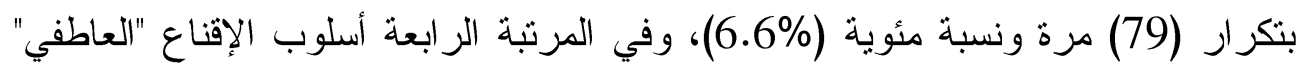
بتكر ار (46) مرة ونسبة مئوية (79\%) مرة ونسية مئو (3.8\%). شكل (ع) أساليب الإقناع المستخدمة في عرض القضايا السياسية

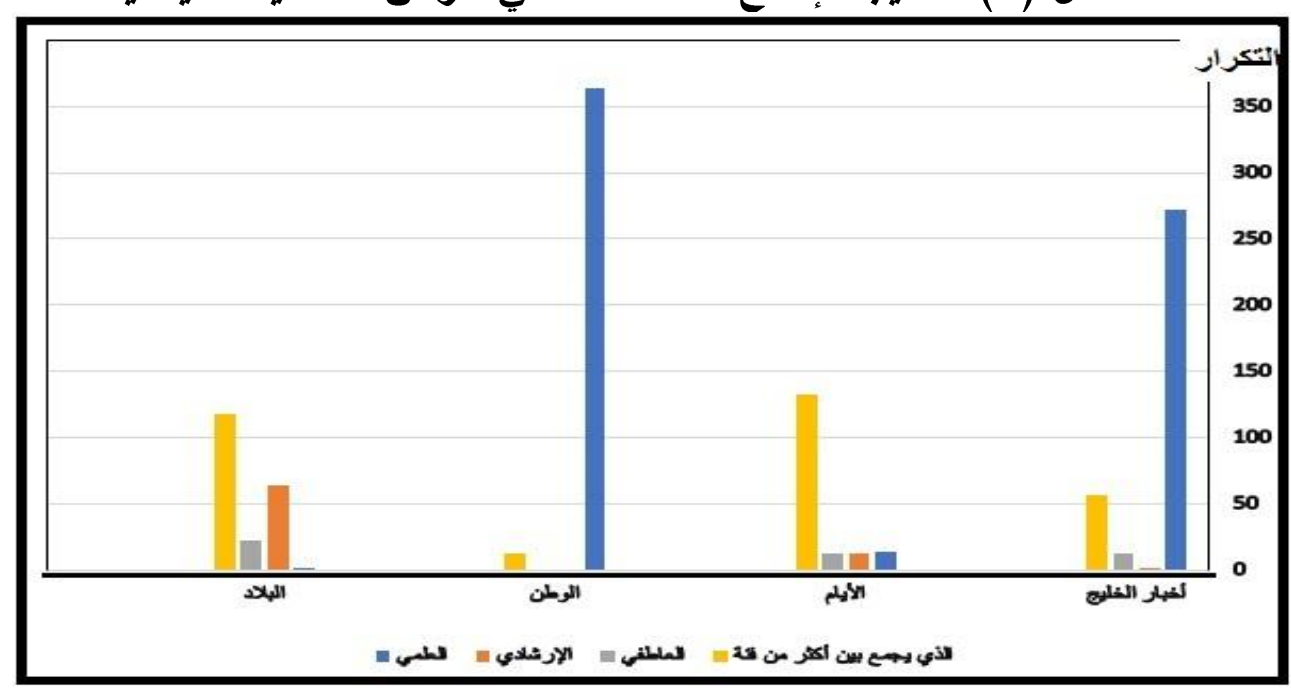




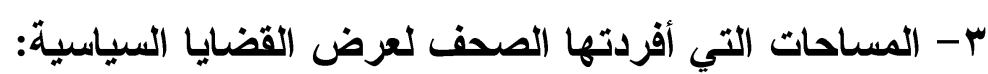
يظهر شكل (0) أن أكثر الصحف البحرينية ركزت على الصفيات المساحات الصغيرة لعرض القضايا السياسية حيث تم نشر (42.9\%) من القضايا السياسية في مساحة " أقل رئل

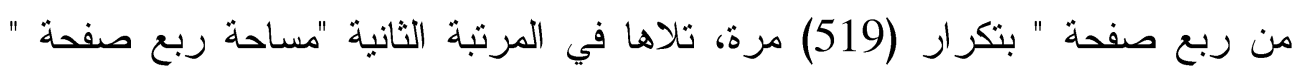
بتكر ار (422) مرة ونسبة مئوية (34.9\%)، ثم " نصف صفحة " في المرنبة الثالثة

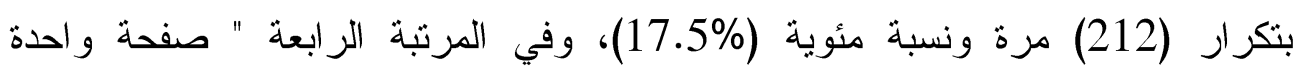
“بتكر ار (52) مرة ونسبة مئوية (4.3\%)، ثم " صفحتان " في المرتبة الخامسة بتكر ار

شكل (ه) المساحات المفردة للقضايا السياسية في الصحف البحرينية

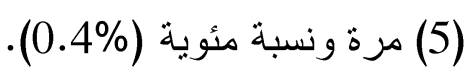

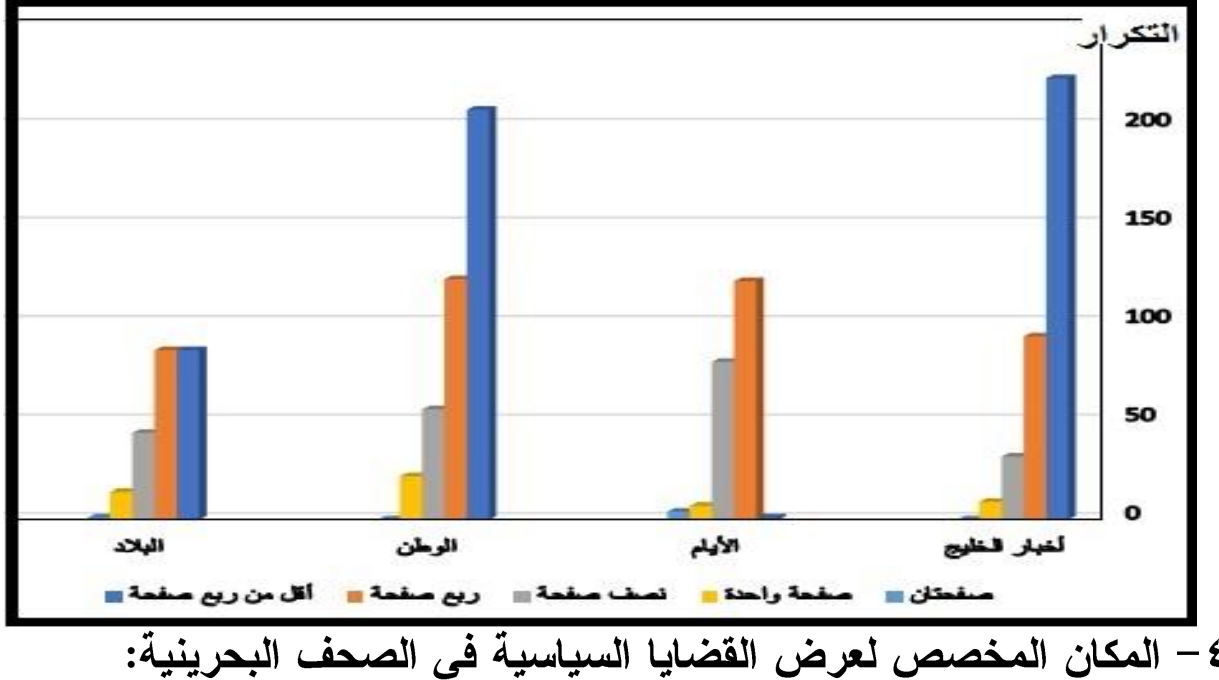

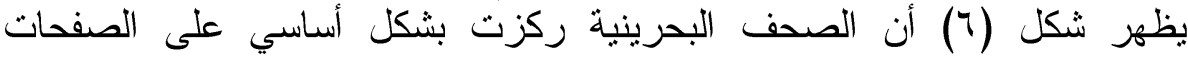

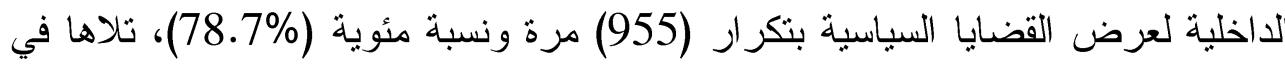
المرتبة الثانية "الصفحة الأولى" بنكر ار (220) مرة ونسبة مئوية (18.1\%)، ثم "الصفحة

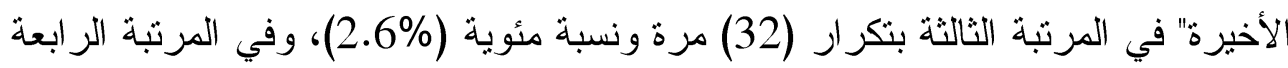
"الملاحق" بتكر ار (6) مر ات ونسبة مئوية (0.5\%). 


\begin{tabular}{|c|c|}
\hline$(r, Y)$ & حوليات آداب عين شمس - المجلد 9 ؟ \\
\hline
\end{tabular}

شكل (آ) المكان المخصص لعرض القضايا السياسية في الصحف البحرينية

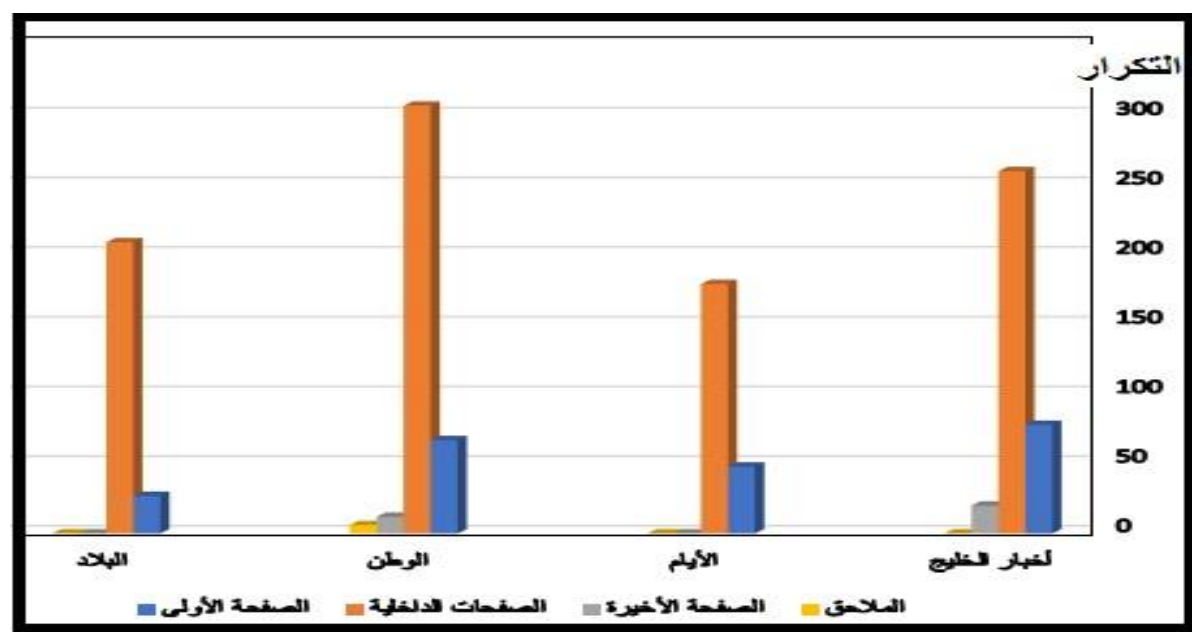

ه - المصادر الصحفية التي استخدمت في عرض القضايا السياسية:

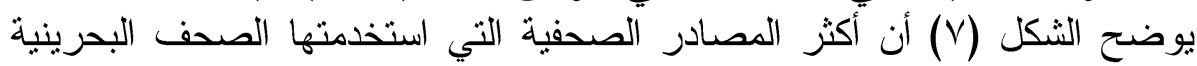

لعرض القضايا السياسية هي "وكالات الأنباء المحلية" بتكرار (412) مرة ونسبة مئوية (32.3\%)، تلاها في المرتبة الثانية "الكاتب الصحفي" بتكر ار (339) مرة ونسبة مئوية (26.6\%)، ثم "تصريح من مسؤول" في المرتبة الثالثة بتكرار (209) مرة ونسبة مئوية

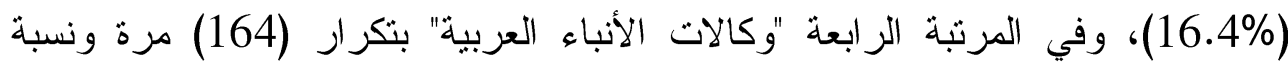
مئوية (12.9\%)، ثم "وكالات الأنباء الأجنبية" في المرنبة الخامسة بتكرار (58) مرة

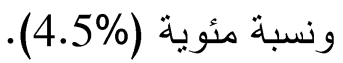

شكل (V) مصادر المعلومات التي استخدمت لعرض القضايا السياسية.

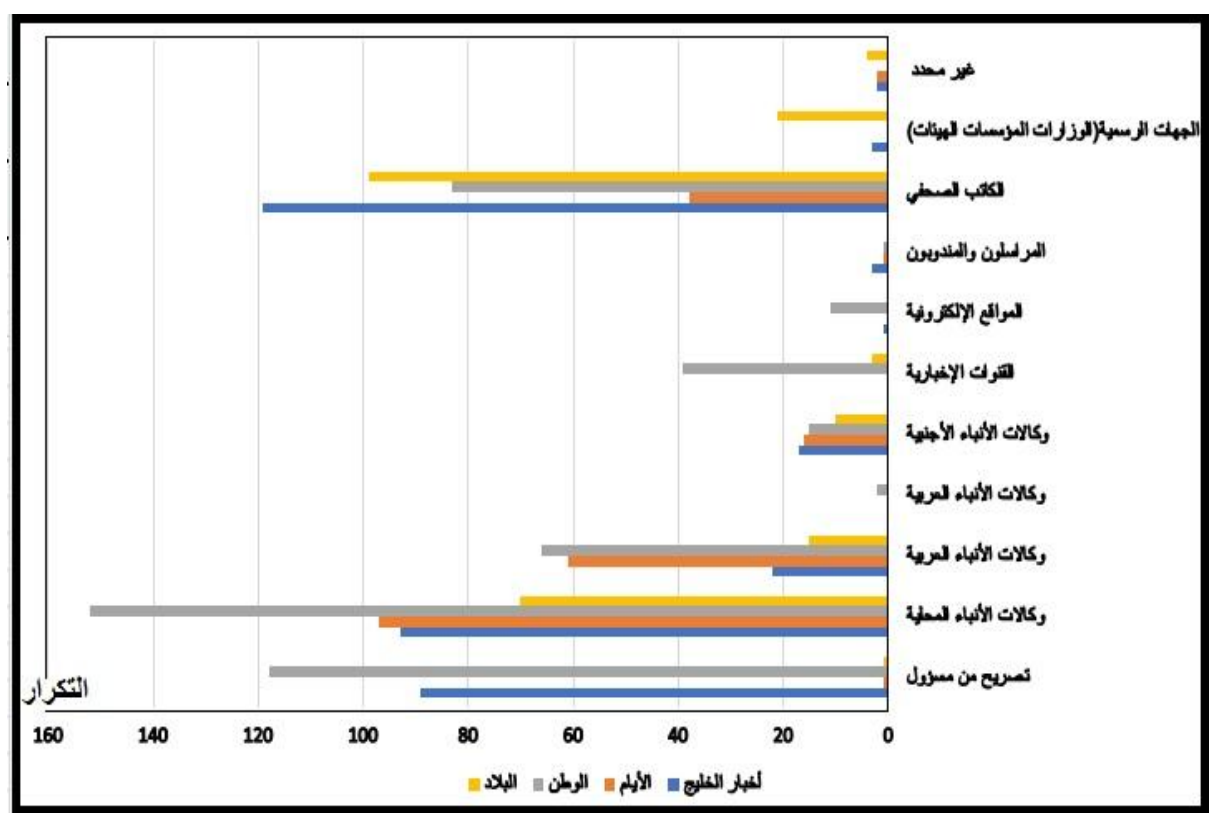

$-1 \leqslant \varepsilon-$ 
צ- اتجاهات الصحف نحو القضايا السياسية:

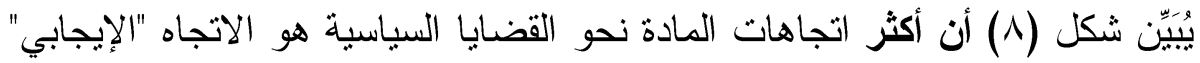

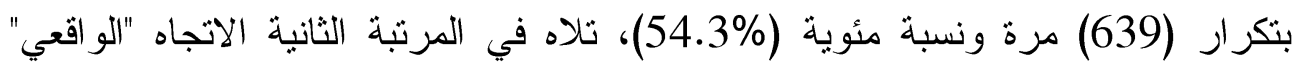

بتكر ار (364) مرة ونسبة مئوية (31.0\%)، ثم الاتجاه "السلبي" في المرتبة الثالثة بتكر ار (101) مرة ونسبة مئوية (8.6\%)، وفي المرنبة الر ابعة الاتجاه "المحايد" بتكرار (48) مرة ونسبة مئوية (4.1\%)، ثم "التوجهات الأيديولوجية" في المرنبة الخامسة بتكرار (15) مرة ونسبة مئوية (1.3\%).

شكل (^) اتجاه الصحف البحرينية نحو القضايا السياسية

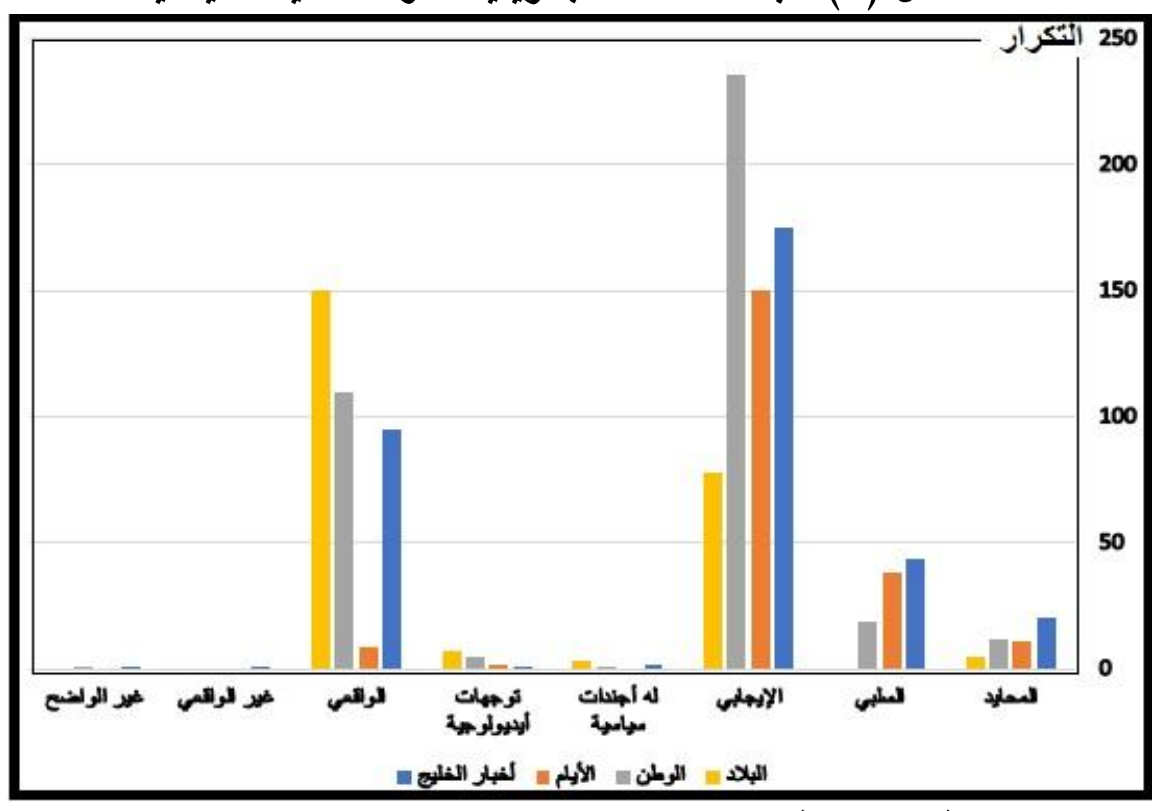

ب- نتائج الادراسة المبدانبة:

تقيد الدراسات الميدانية في معرفة الجاهات الجمهور البحرينية نحو أساليب

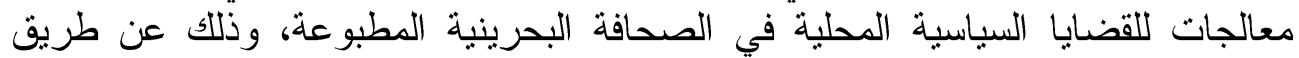

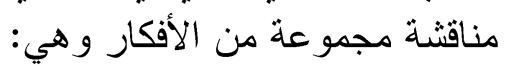

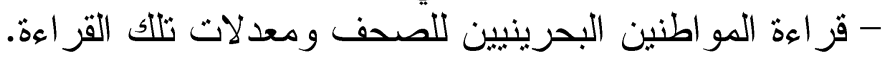
- مصادر البيانات التي يعتمد عليها المو اطنين في معرفة القضايا السياسية.

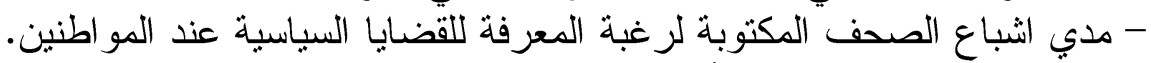
- طرف تحقق الجمهور من الأخبار المكتوبة. - مدي تأثثر الصحف الحمثن المكتوبة في الر أي العام البحريني سياسيًا.

\section{ا. مدى ومعدلات قراعة العينة للصحف:}

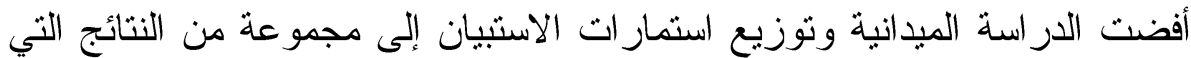

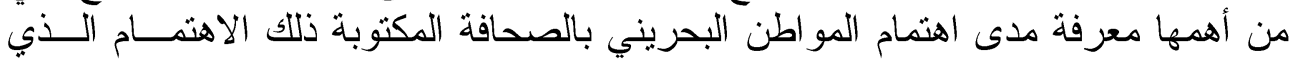

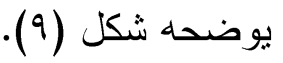




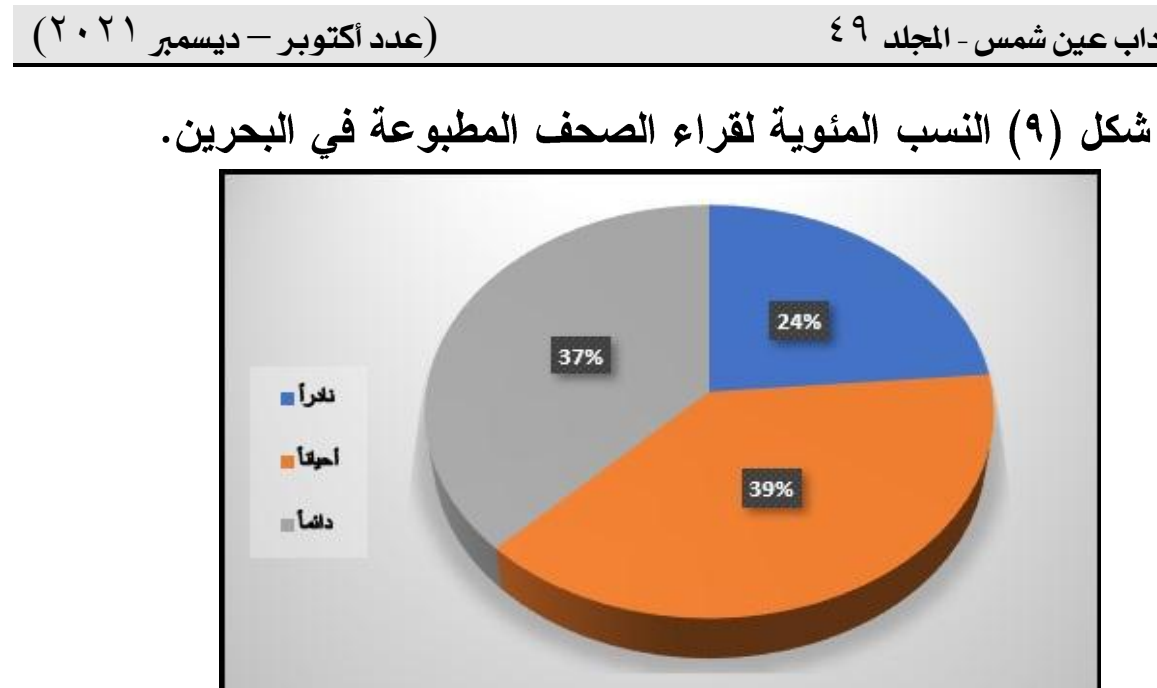

تظهر نتائج الشكل السابق أن ما نسبته (37.6\%) من عينة الدراسة دائما تقر أ

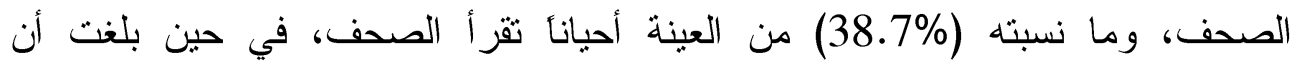

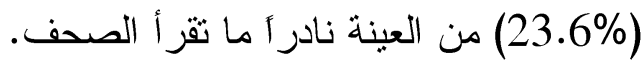
أما عن معدل قراعة العينة للصحف البحرينية فتم حساب التكرارات والتهل النسب المئوية

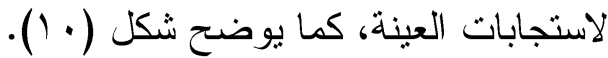
شكل ( • 1) معدل قر اعة العينة للصحف البحرينية

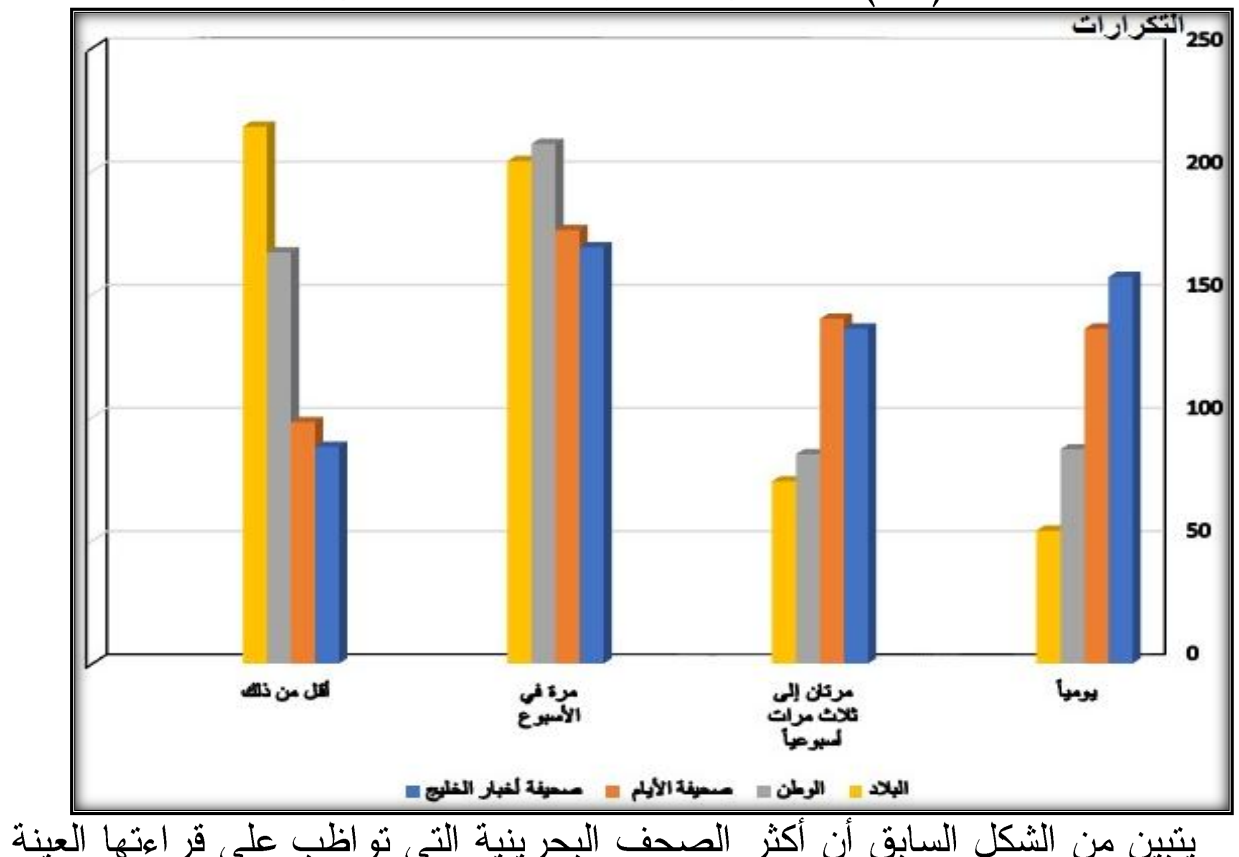
هي "صحيفة أخبار الخليج" بمتوسط حسابي (2.658)، حيث بقر أها ما نسبته (28.5\%)

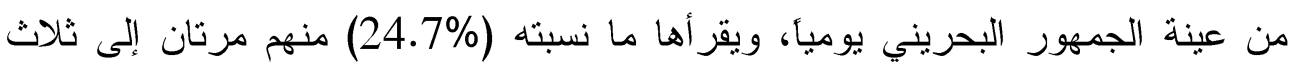

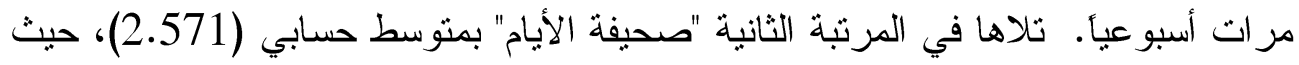
يقزأها ما نسبته (24.7\%) من عينة الجمهور البحريني يوميأ، ويقرأها ما نسبته 
(25.5\%) منهم مرتان إلى ثلاث مرات أسبوعيأ. وجاءت في المرتبة الثالثة "صحيفة الوطن" بمتوسط حسابي (2.167)، حيث يقر أها ما نسبته (15.8\%) من عينة الجمهور البحريني يوميأ، ويقر أها ما نسبته (15.5\%) منهم مرنان إلى ثلاث مرات أسبو عياً. ثم في المرثبة الر ابعة "صحيفة البلاد" بمنوسط حسابي (1.935)، حيث يقر أها ما نسبته (9.8\%) من عينة الجمهور البحريني يوميأ، ويقر أها ما نسبته (13.5\%) منهم مرنان إلى ثناث مر ات أسبو عيأ.

Y. مصادر البيانات التي يعتمد عليها المواطنين في معرفة القضايا السياسية:

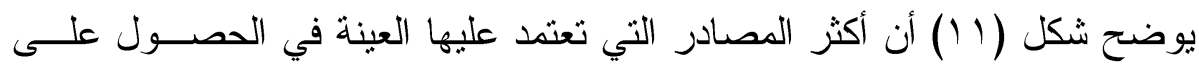

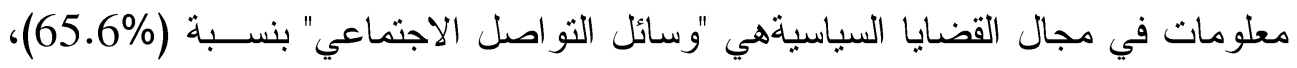
تلاها في المرثبة الثانبة "الصحف المحلية المطبوعة" بنسبة (44.0\%)، وجاءت "القنــوات ات الفضائية الإخبارية بالعربية" في المرتبة الثالثة بنسبة (42.5\%)، ثم "الإنترنت (المو اقـع

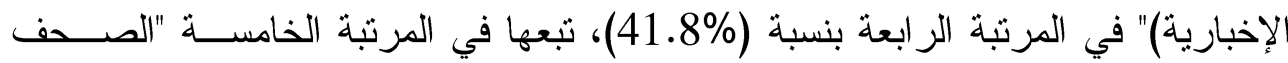
المحلية الإكترونية" بنسبة (15.8\%).

شكل (11) مصادر البيانات التي يعتمد عليها المواطنين في معرفة القضايا

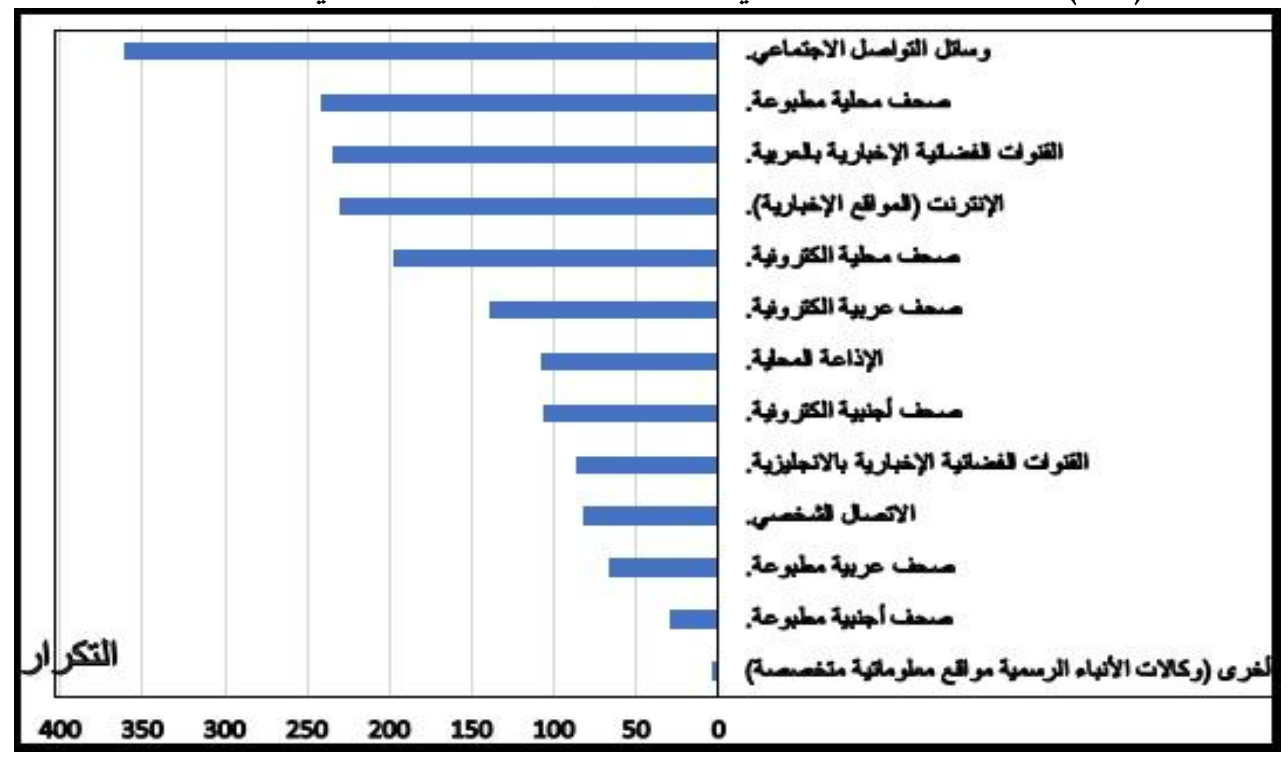

r. اشباع الصحف المكتوبة لرغبة المعرفة للقضايا السياسية عند المواطنين: يظهر شكل (Y I) أن ما نسبته (43.1\%) من عينة الدراسة أكدوا على أن المواد الإخبارية في الصحف البحرينية تشبع احتياجاتهم نحو القضايا السياسية، وما نسبته (56.9\%) منهم أكدو ا على أن المو اد الإخبارية في الصحف البحرينية لا نشبع احتياجاتهم نحو القضايا السياسية. 
شكل (Y r) إثباع المادة الإخبارية في الصحف البحرينية احتياجات العينة نحو القضاياً السياسية في الصية

ع. طرق تحقق الجمهور من الأخبار المكتوبة:

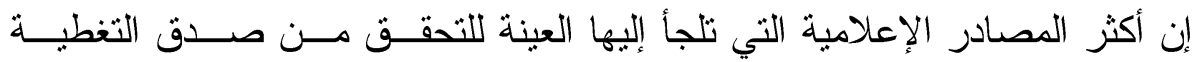
الإعلامية هي "وسائل التو اصل الاجنماعي" بنسبة (56.9\%)، تلاها في المرتبـــة الثانبــة

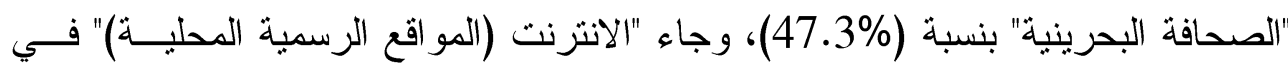

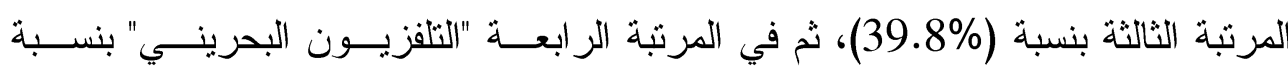

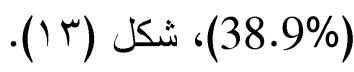
شكل (T) التكرارات والتسب المئوية للمصادر الإعلامية التي تلجأ إليها العينة

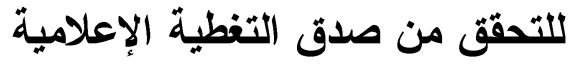

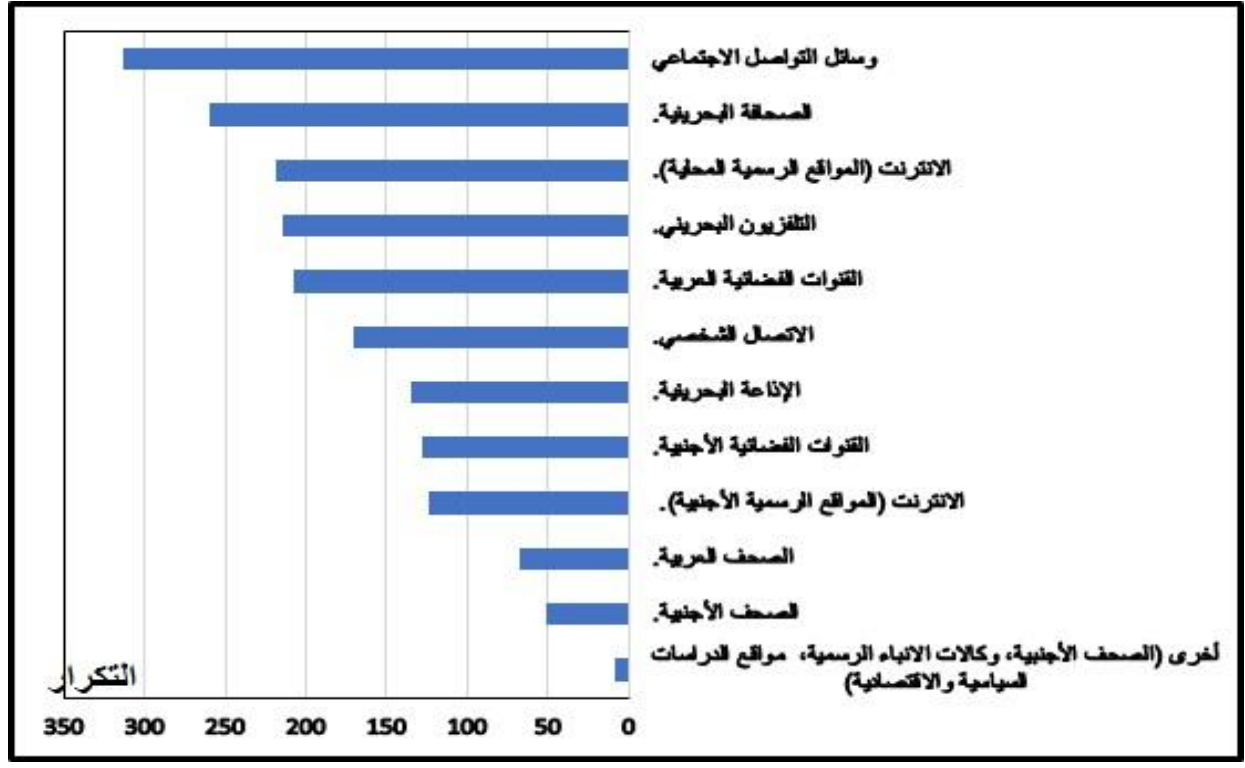


هـ قدرة الصحف البحرينية على التأثير على الجمهور البحريني من خلال تثكيل مواقفه

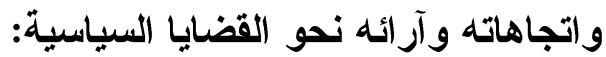

أكدت الدراسة الميدانية أن ما نسبته (43.1\%) من عينة الدراسة أكدو العلى قدرة الصحف البحرينية على التأثير على الجمهور البحريني من خلال تشكيل مو اقفه واتجاهاته و آر ائه نحو القضايا الر اهنة، وما نسبته (40.0\%) منهم أكدو ا على أن الصحف البحرئية

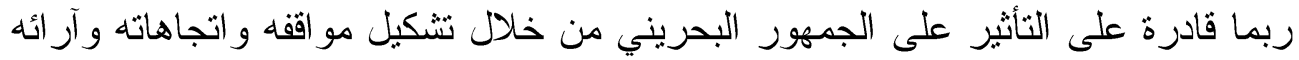

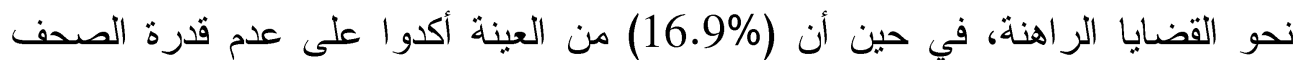

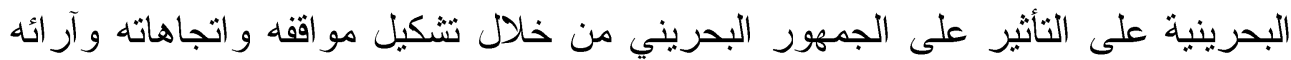
نحو القضايا الر اهنة شكل (ع الثير (1). وتظهر نتائج الثكل(ع ()) أن أكثر صحيفة قادرة على التأثير على الجمهور

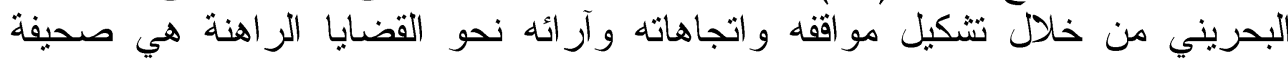

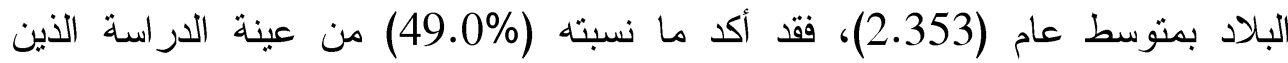
يفضلون هذه الصحيفة على قدرة صحيفة البلاد على التأثير على الجمهور البحريني من

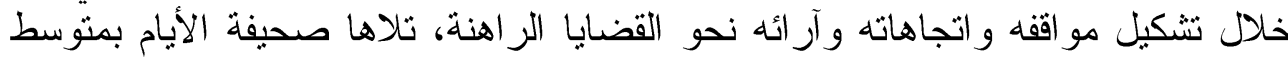
عام (2.347)، فقد أكد ما نسبته (48.3\%) من عينة الدراسة الذين يفضلون هذه ولها الصحيفة على قدرة صحيفة الأيام على التأثثر على الجمهور البحريني من خلامل تشكيل مو اقفه و اتجاهاته و آرائه نحو القضايا الر اهنة، ثم صحيفة الوطن بمنوسط عام (2.278)، فقد أكد ما نسبته (43.5\%) من عينة الدراسة الذين يفضلون هذه الصحيفة على قدرة صحيفة الوطن على التأثير على الجمهور البحريني من خلال تشكيل مواقفه و اتجاهاته و آر ائه نحو القضايا الراهنة، ثم صحيفة أخبار الخليج بمتوسط عام (2.163)، فقد أكد ما لئل نسبته (37.2\%) من عينة الدر اسة الذين يفضلون هذه الصحيفة على قدرة صحيفة أخبار

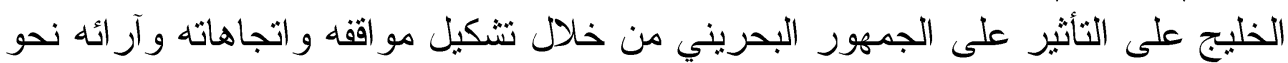

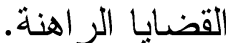

شكل (ع 1) تأثير الصحف البحرينية على الجمهور البحريني من خلا تل تشكيل مواقفه واتجاهاته وآرائه نحو القضايا التيا السياسية.

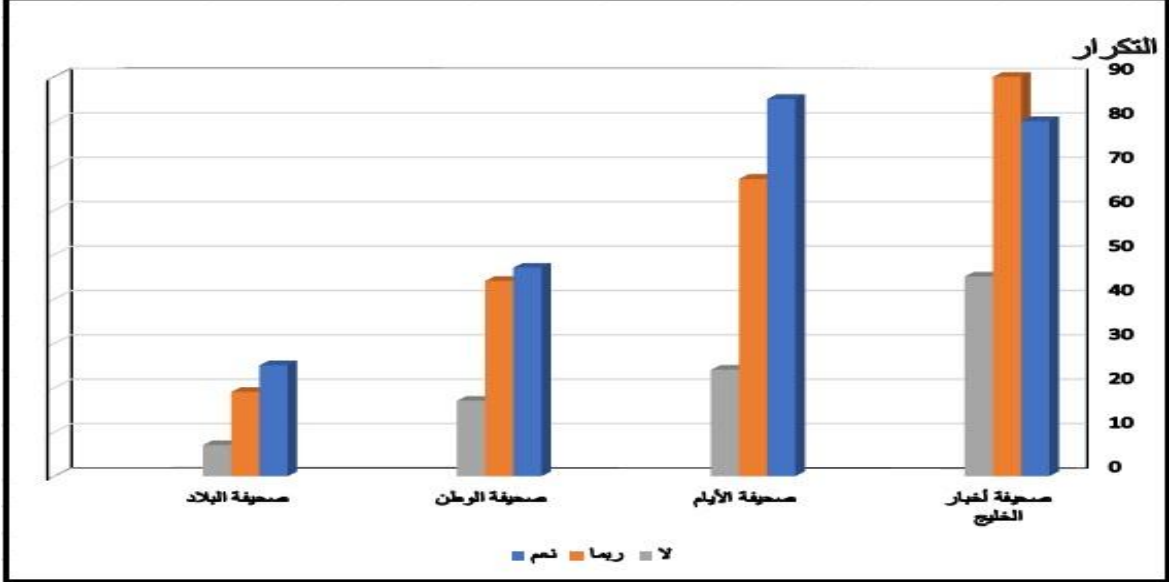




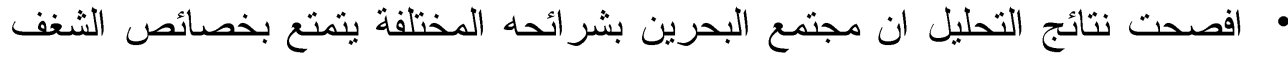

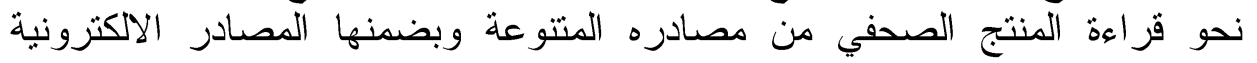
ووسائل التو اصل الاجتماعي. فضلا عن اهتماماته المتتوعة المتعلقة بالقضايا السياسية

$$
\text { و المستجدات على الساحتين الخليجية و العالمية. }
$$

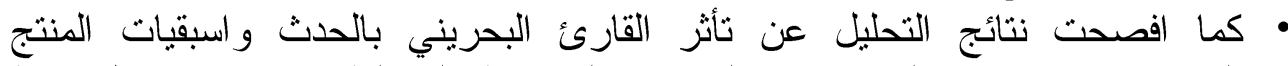

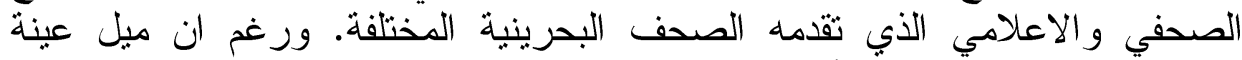

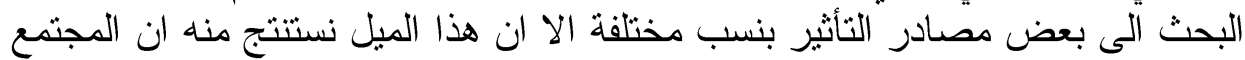

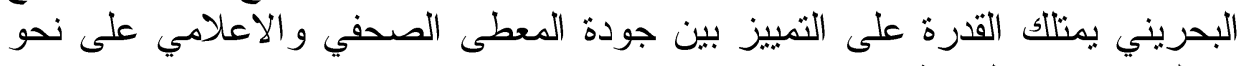

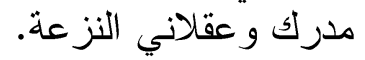

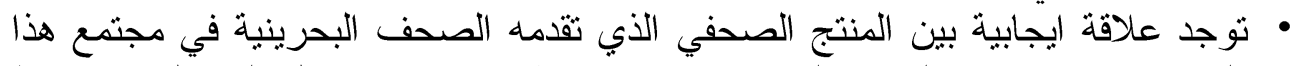

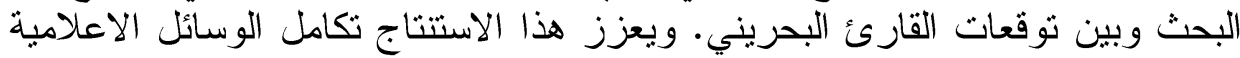

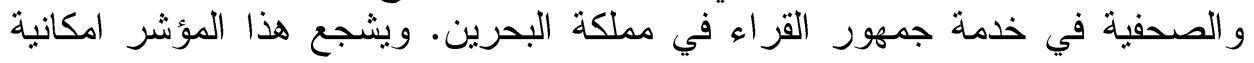
تعميق معايير جودة المنظومة الصحفية والاعلامية على نحو المعايير العالمية في هذا

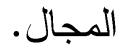

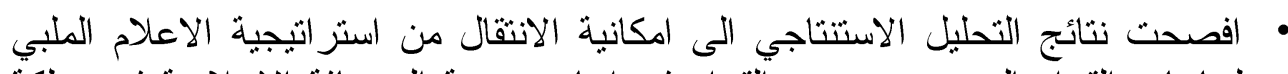

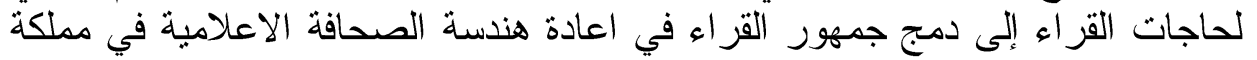

• و اشتارت معطيات الاختبار ات الاحصائية الى استتناج مفاده ان العو امل الديموغر افية

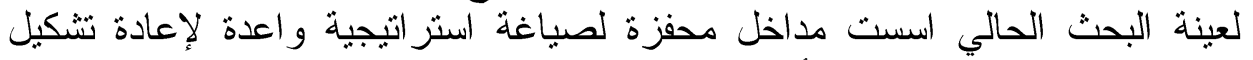

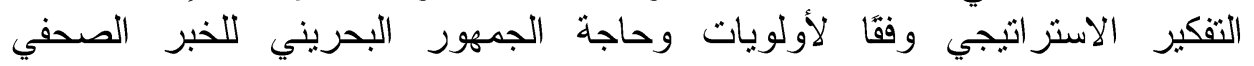

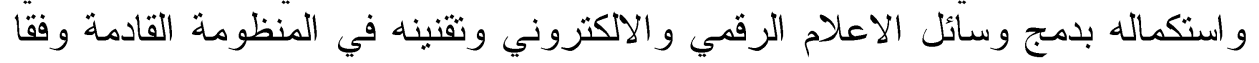
لمتضمنات الرؤية الاقتصادية لمملكة البحرين الاعين 


\section{التوصبات:}

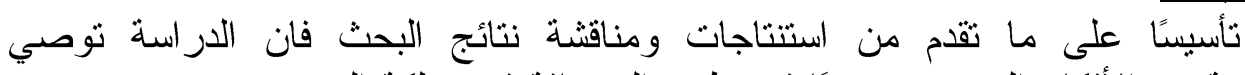
بمجموعة من الأفكار التي تسهم حنمًا في تطور الصحافة في مملكة فئة البحرين:

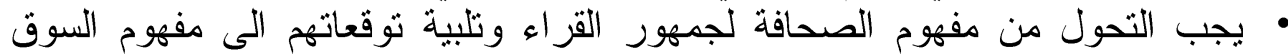

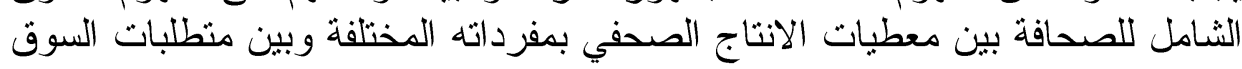

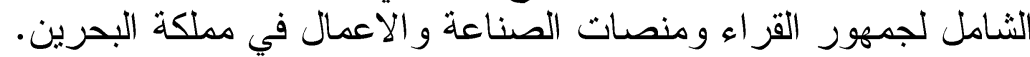

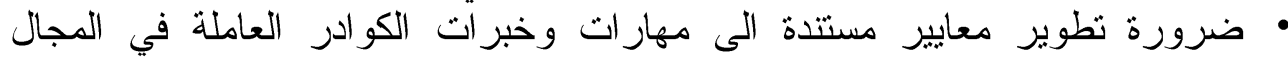

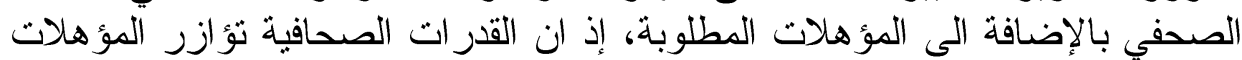

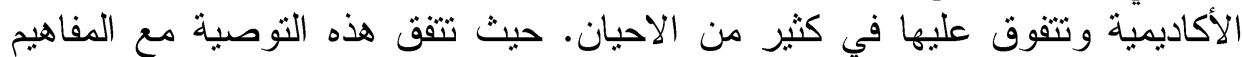

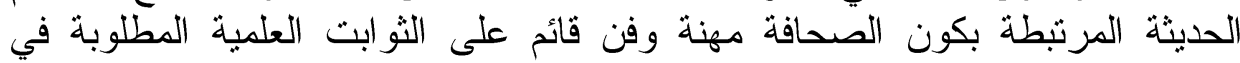
تشغيل منظومة صحفية عالمية المعايير ومحلية التشغيل. • افصحت استتناجات البحث معززة بنتائج البحث الاستنتاجي الى ميل القارئ البئ البحريني

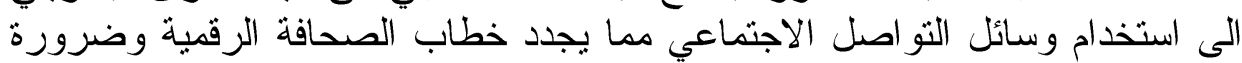
تقنينها وتأسيس ضوانط استخدامها كونها أصبحت واتيات واقعا ليس في مملكة البحرين

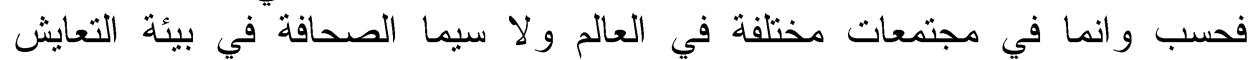

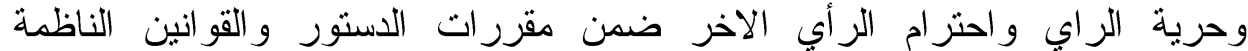

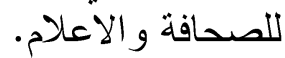

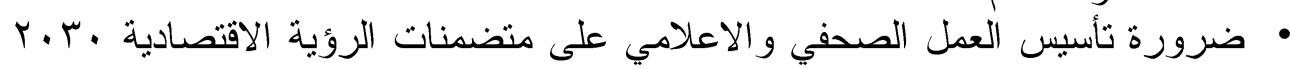

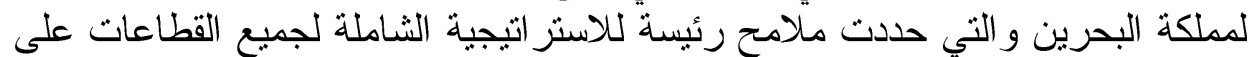

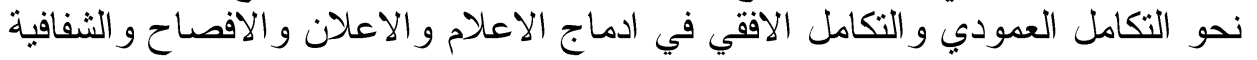

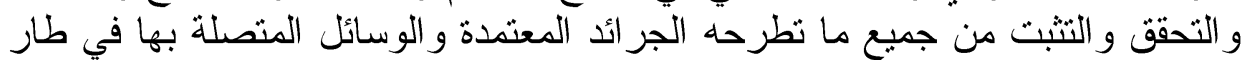
المشروع الاصداحي و البرنامج الحكومي في مملكة البحرين. 


\section{Abstract \\ The impact of the Bahraini newspapers on political news on the Bahraini public opinion \\ By Khaled Zaied Ali}

The press in the Kingdom of Bahrain represents one of the most influential channels of influencing public opinion towards political issues. This is accomplished through the achievement of a set of objectives, the most important of which is the knowledge of the arts, methods, sources and trends used by the newspapers to present political issues, in addition to the extent to which the public read the Bahraini newspapers, the sources that rely on them to obtain information on political issues.

The study relied on the media survey methodology, the use of content analysis tools and the questionnaire for data collection.

The importance of the study is to evaluate the way local political issues are dealt with in the media, and to present proposals to media officials and political leaders on what should be the press article dealing with such issues, especially considering the lack of Arab studies on this subject.$$
\text { الامهو امش }
$$$$
\text { ' محمد فوزي شهاب الدين، دور التلفزيون في ترتيب أولويات القضايا السياسية لدى الجمهور البحريني }
$$

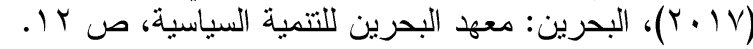

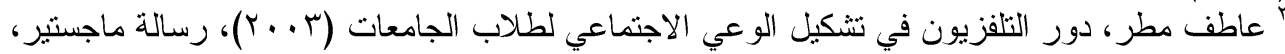

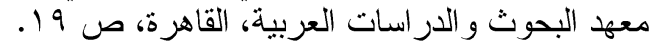

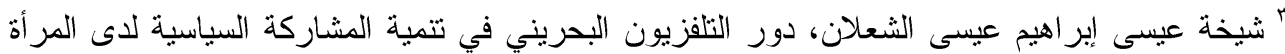

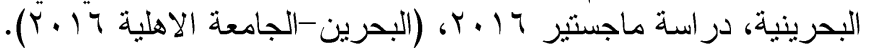

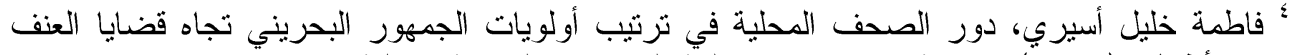

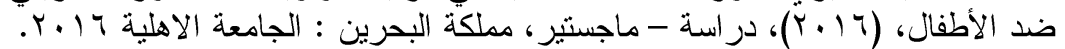

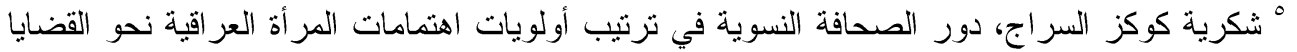

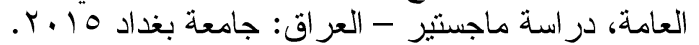

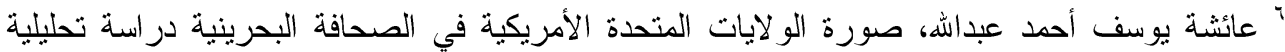

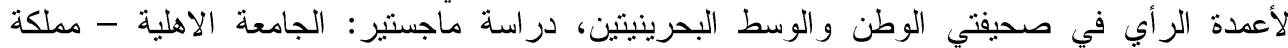

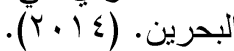$$
\text { ل لشوى يوسف اللواتي، تأثير التعرض للمواقع الإخبارية الالكترونية في تشكيل اتجاهات الجمهور }
$$

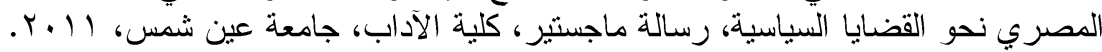

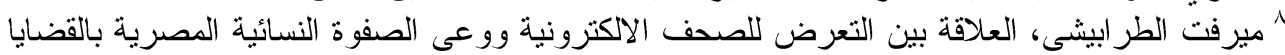

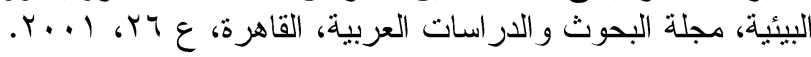

${ }^{9}$ Harris, Phil \& Others, Who sets the Agenda? On analysis of agenda setting the press and television coverage in the 1999 Greek European election in: European journal of marketing, Vo; .35, No.9, 2001.

${ }^{10}$ Jessica T. Feezell, Agenda Setting through Social Media: The Importance of Incidental News Exposure and Social Filtering in the Digital Era, Political Research Quarterly, Volume: 71 issue: 2, 2017 page(s): 482-494
} 


$$
\begin{aligned}
& \text { ' أحمد زكي بدوي." معجم مصطلحات العلوم الاجتماعية"، مكتبة لبنان، ـ99 19، صباه }
\end{aligned}
$$

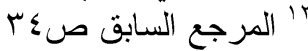

$$
\begin{aligned}
& \text { "'ا أحمد العابد و آخرون." المعجم العربي الأساسي"، المنظمة العربية للتربية و التقافة، دمشق، ص101 }
\end{aligned}
$$

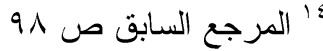

15 Jessica T. Feezell, Agenda Setting through Social Media: The Importance of Incidental News Exposure and Social Filtering in the Digital Era, Political Research Quarterly, Volume: 71 issue: 2, 2017 page(s): 483

أحمد العابد و آخرون، (990 (190)، " المعجم العربي الأساسي"، المنظمة العربية للتربية و التقافة، دمشق.

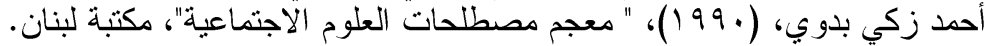

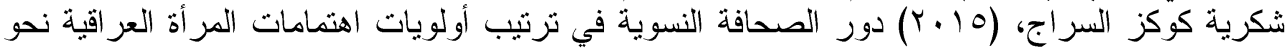

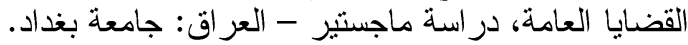

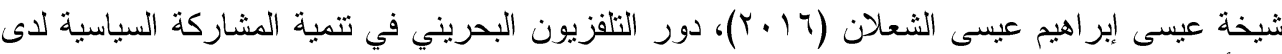

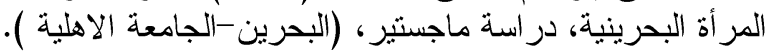

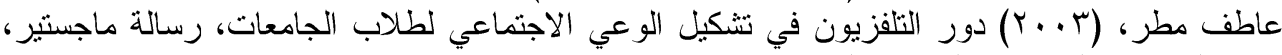

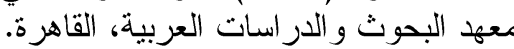

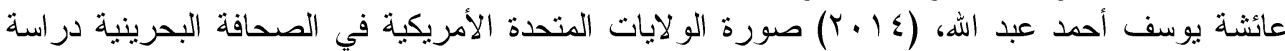

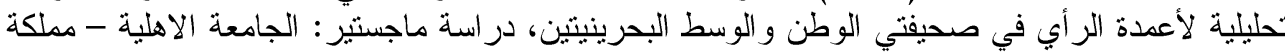
البحرين. فاطمة خليل أسيري، (T ( • (Y)، دور الصحف المحلية في ترتيب أولويات الجمهور البحريني تجاه قضايا

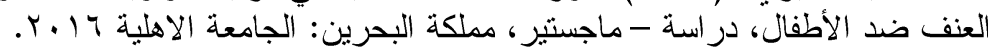

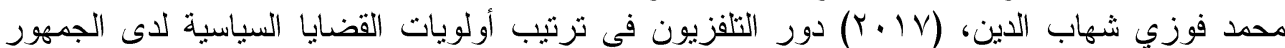

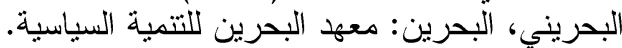

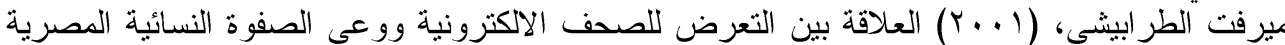

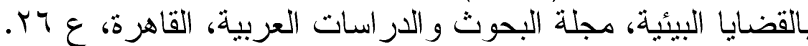

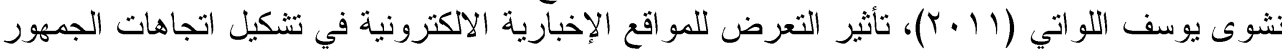

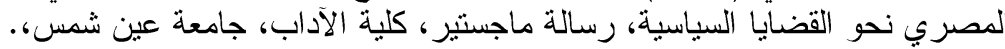

15 Harris, Phil \& Others, who sets the Agenda? On analysis of agenda setting the press and television coverage in the 1999 Greek European election in: European journal of marketing, Vo; .35, No.9, 2001.

15 Jessica T. Feezell, Agenda Setting through Social Media: The Importance of Incidental News Exposure and Social Filtering in the Digital Era, Political Research Quarterly, Volume: 71 issue: 2, 2017 page(s): 482-494 